\title{
Antimicrobial susceptibilities in dairy herds that differ in dry cow therapy usage
}

\section{S. McDougall, ${ }^{1 *}$ ๑ J. Penry, ${ }^{1}$ and D. Dymock ${ }^{2}$ \\ ${ }^{1}$ Cognosco, Anexa, PO Box 21, Morrinsville 3300, New Zealand \\ ${ }^{2}$ MSD, Upper Hutt 5140, New Zealand}

\begin{abstract}
Intramammary infusion of antimicrobials at the end of lactation (dry cow therapy; DCT) is a central part of mastitis control programs and is one of the major indications for antimicrobial use in dairy cows. However, with increasing focus on prudent use of antimicrobials and concerns about emergence of antimicrobial resistance, the practice of treating every cow at the end of lactation with DCT is in question. This cross-sectional, observational study determined the minimum inhibitory concentrations (MIC) of 10 antimicrobials for coagulase-negative staphylococci (CNS), Staphylococcus aureus, Streptococcus dysgalactiae, and Streptococcus uberis isolates from milk samples from dairy cows with somatic cell counts $>200,000$ cells $/ \mathrm{mL}$ in herds that had been organic for $>3$ yr $(n=7)$, or had used either ampicillin-cloxacillin DCT $(\mathrm{n}=11)$ or cephalonium DCT $(\mathrm{n}=8)$ in the preceding $3 \mathrm{yr}$. The organic herds were certified under the United States Department of Agriculture National Organic Program, meaning that there was no blanket DCT, and minimal use of antimicrobials in general, with a loss of organic status of the animal if treated with antimicrobials. Breakpoints (where available) were used to categorize isolates as resistant, intermediate, or susceptible to antimicrobials. The MIC distributions of isolates from different herd types were compared using binomial or multinomial logistic regression. Of 240 CNS isolates, 12.9, 0.8, $7.1,32.6$, and $1.2 \%$, were intermediate or resistant to ampicillin, cephalothin, erythromycin, penicillin, and tetracycline, respectively. Of 320 Staph. aureus isolates, $29.0,2.5,1.2$, and $34.9 \%$ were intermediately resistant or resistant to ampicillin, penicillin, erythromycin, and oxacillin, respectively. Of 184 Strep. uberis isolates, $1.1,25.0,1.6$, and $1.6 \%$ were intermediately resistant or resistant to erythromycin, penicillin, pirlimycin, and tetracycline, respectively. Generally, the MIC of CNS
\end{abstract}

Received November 17, 2020.

Accepted March 28, 2021.

*Corresponding author: smcdougall@anexafvc.co.nz and streptococcal isolates from organic herds were lower than isolates from herds using DCT. However, the differences in MIC distributions occurred at MIC below clinical breakpoints, so that the bacteriological cure rates may not differ between isolates of differing MIC. Bimodal distributions of MIC for ampicillin and penicillin were found in Staph. aureus isolates from organic herds, suggesting that isolates with a higher MIC are a natural part of the bacterial population of the bovine mammary gland, or that isolates with higher MIC have persisted within these organic herds from a time when antimicrobials had been used. Given these observations, further work is required to determine if exposure to DCT is causally associated with the risk of elevated MIC, and whether reduction or removal of DCT from herds would reduce the risk of elevated MIC of mastitis pathogens.

Key words: antimicrobial resistance, mastitis, dry cow therapy, dairy cow

\section{INTRODUCTION}

Intramammary infusion of antimicrobials at the end of lactation (i.e., dry cow therapy; DCT) is part of mastitis control programs around the world. Dry cow therapy reduces new IMI and treats existing IMI over the nonlactating period and has been a cornerstone of mastitis control for many decades (Dodd et al., 1969). A meta-analysis reported a $39 \%$ reduction in new IMI over the dry period and a $78 \%$ increase in cure of IMI following DCT infusion, relative to no DCT (Halasa et al., 2009a,b). Dry cow therapy represents one of the most common indications for antimicrobial usage on dairy farms (Pol and Ruegg, 2007; Compton and McDougall, 2014; Stevens et al., 2016). However, with increasing concern about antimicrobial usage in animal agriculture potentially increasing the risk of antimicrobial resistance, use of DCT, particularly to animals without an existing infection, is being questioned (Rajala-Schultz et al., 2004).

$\beta$-lactam antimicrobials are the most commonly used DCT products in New Zealand, with $25 \%$ con- 
taining ampicillin, $61 \%$ containing cloxacillin, and $13 \%$ containing cephalonium, by mass (ACVM, 2019). Resistance to $\beta$-lactam antimicrobials may arise either through production of $\beta$-lactamases or via mutations of the penicillin-binding proteins of the bacterial cell wall (Walsh, 2000). About 30\% of Staphylococcus aureus isolates from bovine mastitis cases were reported to be penicillin-resistant, but there was no evidence of resistance to cloxacillin or cefuroxime in bovine isolates in New Zealand (McDougall et al., 2014). Streptococci are generally penicillin-susceptible, but there is evidence of a bimodal MIC distribution for cloxacillin (GuérinFaublée et al., 2003; Tenhagen et al., 2006; McDougall et al., 2014). The susceptibility of mastitis isolates to cephalonium has not been assessed for mastitis pathogens in New Zealand. However, in French isolates, MIC inhibiting growth of 50\% $\left(\mathbf{M I C}_{\mathbf{5 0}}\right)$ and $90 \%\left(\mathbf{M I C}_{\mathbf{9 0}}\right)$ for Streptococcus uberis were reported as 0.03 and 0.06 $\mathrm{ug} / \mathrm{mL}$, respectively (Poutrel et al., 2018). In European isolates, the $\mathrm{MIC}_{50}$ and $\mathrm{MIC}_{90}$ for cephalonium were 0.12 and $0.25 \mu \mathrm{g} / \mathrm{mL}$ for Staph. aureus, $\leq 0.03$ and 0.06 $\mu \mathrm{g} / \mathrm{mL}$ for Strep. uberis, and $\leq 0.03$ and $\leq 0.03 \mu \mathrm{g} / \mathrm{mL}$ for Streptococcus dysgalactiae, respectively (de Jong et al., 2018). In that same study, the MIC for Staph. aureus and Strep. uberis for other cephalosporins, including cefquinome, ceftiofur, and cephalexin, were higher than for cephalonium.

There is limited evidence that antimicrobial usage in dairy cows in general, or use of DCT specifically, is associated with increased risk of antimicrobial resistance. A survey of bovine mastitis isolates suggested that the prevalence of resistance remained stable for most bacterial-antimicrobial combinations between 1994 and 2001 (Markovec and Ruegg, 2003). Isolates of CNS from cows in herds that used antimicrobials were more likely to be resistant than isolates from herds that did not use antimicrobials. However, there was no difference in the $\mathrm{MIC}_{90}$ of cephalothin or ceftiofur for isolates of Staph. aureus or streptococci from organic and conventional farms (Pol and Ruegg, 2007). Despite an association being found between increasing parental antibiotic use and elevated MIC in CNS isolates from bovine milk, there was no association between intramammary antimicrobial usage and elevated MIC in the same CNS isolates (Nobrega et al., 2018). Similarly, in a study where Staph. aureus was isolated from the bulk tank milk of conventional or organic farms in Denmark and the United States, there was no difference in the MIC distributions for cephapirin (Sato et al., 2004). In another study from the United States, the prevalence of resistance to penicillin in CNS from cows that had received DCT was numerically higher than in isolates from heifers that had not received DCT (39 vs. 24\%), although this difference was not statistically significant (Rajala-Schultz et al., 2004).

The objective of the current study was to compare the distribution of MIC for the common mastitis pathogens, CNS, Staph. aureus, and streptococci from cows that received DCT containing primarily cephalonium or ampicillin-cloxacillin or cows from organic herds that had not used any antimicrobial therapy in pasturebased New Zealand herds. The null hypothesis for the study was that there would be no difference in MIC among isolates from organic compared with DCT-using farms.

\section{MATERIALS AND METHODS}

Care of the animals complied with the New Zealand Animal Welfare Act 1999. Before study initiation, approval from the Ruakura Animal Ethics Committee (AgResearch) was sought and granted (study number 14294). Written informed consent was obtained from herd owners before study commencement.

This observational study was conducted in 26 springcalving dairy herds in the Waikato region of New Zealand that were serviced by 1 veterinary business. Of these herds, 7 were organic; that is, they were certified to have met the United States Department of Agriculture National Organic Program and had not routinely used any antimicrobial treatments in the last 3 yr. These farms had been certified organic for a median of $12 \mathrm{yr}$ (range 7-19 yr). Use of any antimicrobials under this certification results in exclusion from organic supply status for that animal, and thus generally any animals treated are removed from the farms. Eleven herds had predominantly used DCT containing cloxacillin-ampicillin, and 8 herds had predominantly used DCT containing cephalonium DCT in the last 3 yr; hence, comparisons were made between the organic farms and those using cloxacillin-ampicillin or those using cephalonium.

Cows were managed and fed on pasture containing predominantly ryegrass (Lolium perenne) and white clover (Trifolium repens). Supplementary feeding with palm kernel expeller, maize silage, or pasture silage occurred on some farms. Cows were milked twice daily.

Under New Zealand Agricultural Compounds and Veterinary Medicines Act of 1997, veterinarians may authorize the sale of, and holding of, supplies on farm of some registered veterinary medicines. Such authorization includes conditions such that the veterinarian has a knowledge of the disease and management of the farm, and conditions upon the farmers that include the need to have locked storage and to maintain records of usage and of stock held. Authorizations are for a 4-mo 
interval for critically important antimicrobials or 12 mo for other compounds. Farmers are additionally audited by the milk buyers for drug use, recording, storage, and product expiration dates. Hence, there is likely to be a high correlation between sales and on-farm usage, although the exact timing of the sales relative to date of usage may vary. Herds using antimicrobials were selected based on records of the number of doses of DCT sold over the preceding 3 yr (i.e., 2015, 2016, and 2017) extracted from the veterinary practice database. For each herd, the number of cows treated with DCT each year was estimated as the number of doses sold divided by 4 (i.e., assuming each quarter of each cow was infused with 1 dose of DCT). The estimated percentage of cows treated in each herd was determined by dividing the total number of cows in the herd (derived from the maximum number of animals present at herd testing or pregnancy diagnosis) by the estimated number treated. It was assumed that where "blanket" DCT was used, approximately 75 to $80 \%$ of the herd would be treated, as approximately $20 \%$ of cows in New Zealand dairy herds are culled each year. Herds were then selected on the basis that $>50 \%$ of cows were treated in each of the 3 previous years with 1 DCT product. The DCT products were categorized into those containing cloxacillin benzathine (500 or $600 \mathrm{mg}$ ), cloxacillin (500-600 mg) and ampicillin (250-300 mg) combination products, or cephalonium (250 mg).

Herds were also selected on the basis of willingness of the herd owner to allow access to their animal data via electronic databases, to follow enrollment requirements, and the availability of on-farm records where electronic records were not available (e.g., treatment records). Following enrollment of a herd, cow-level data, including cow age, calving date, current lactation SCC, and any treatment records were recovered from a database (Mindapro, LIC), or on-farm recording systems, and loaded into a purpose-built database (Access 2016, Microsoft).

The herd-level use of antimicrobials was estimated by extracting antimicrobial sales data for each herd for the $3 \mathrm{yr}, 2015$ to 2017. For each antimicrobial, the mass (mg) of active was calculated for each milliliter (for injectable antimicrobials) or each intramammary syringe. The total mass per unit was multiplied by the number of units sold to calculate the total mass for each product for the herd, and then the mass of all products summed within each calendar year. The total mass was then divided by the number of cows in the herd and the assumed mass of an average New Zealand dairy cow $(450 \mathrm{~kg})$ to determine the total mass of antimicrobials used per kilogram of liveweight per year for each herd. The mass of each class of antimicrobial per kilogram of liveweight per year was also calculated.

\section{Milk Sample Collection}

Milk samples were collected between September 26, 2017, and January 22, 2018, when the cows were on average $( \pm$ SD) $101 \pm 34$ (range $15-239$ ) DIM. The timing of sampling was on a convenience basis, but on the basis that at least 1 production recording (herd test) had been undertaken after the start of the seasonal calving period. Cows were selected from each enrolled herd that had had at least 1 lactation, had been treated with DCT (in those herds using DCT), had not been treated with any other antimicrobial within $30 \mathrm{~d}$ before sample collection (to maximize the chance of isolating bacteria when sampled), and had an individual SCC of $>200,000$ cells $/ \mathrm{mL}$ at the most recent production recording. The cut-point of $>200,000$ cells/ $\mathrm{mL}$ was chosen as it is internationally-accepted and has a reported sensitivity and specificity for detection of an intramammary infection of 0.73 and 0.86 , respectively (Dohoo and Leslie, 1991).

Duplicate milk samples $(\sim 1-5 \mathrm{~mL})$ were collected into factory-clean, polyethylene sample vials (Biolab) from each mammary gland following aseptic teat-end preparation and discard of the first 3 strips of milk. The sample vials were labeled with herd, date, cow number, and quarter. These samples were held at ambient temperature for a maximum of $8 \mathrm{~h}$ before being stored at $-20^{\circ} \mathrm{C}$ until processing.

\section{Laboratory Procedures}

Microbiology was undertaken by trained technicians at Cognosco, Anexa. One of the duplicate milk samples was thawed at room temperature for $<24 \mathrm{~h}$ for processing. Microbiology was undertaken following the recommendations of the National Mastitis Council, USA (Middleton et al., 2017). Briefly, $10 \mu \mathrm{l}$ of milk was streaked onto a quarter of a $5 \%$ blood agar plate containing $0.1 \%$ esculin (Fort Richard) and incubated at $37^{\circ} \mathrm{C}$ for $48 \mathrm{~h}$. The bacterial genus or species was determined based on colony morphology, Gram stain, esculin reaction, coagulase, inulin, and Streptococcus faecalis broth tests. Staphylococcus aureus were defined as gram-positive, catalase- and coagulase-positive cocci. Streptococci were defined as gram-positive, catalasenegative cocci and further speciated by growth in inulin and failure to grow in Streptococcus faecalis broth. The Strep. dysgalactiae and Strep. uberis were differentiated based on esculin reaction (positive for Strep. uberis), colony morphology, and CAMP test (negative for Strep. dysgalactiae). Gram-negative rods were subcultured onto MacConkey's agar, and appropriate biochemical tests were undertaken to speciate. For 2 gram-negative isolates, where the identity of the isolate was unclear 
using conventional biochemical tests, MALDI-TOF MS was used to identify the isolate. Quarters were defined as infected and the isolate preserved where $>1 \mathrm{cfu}$ of a major pathogen was found, other than for Staph. aureus, where a single colony forming unit was defined as infection (Dohoo et al., 2011). Two distinct bacterial species were isolated from 117 quarter samples and both these were preserved for subsequent MIC determination. A contaminated sample was defined as presence of $>2$ distinct colony types, and no isolates were kept from such samples.

Isolates defined as Staph. aureus, CNS, Strep. dysgalactiae, or Strep. uberis were preserved on cryobeads (Fort Richard) and held at $-80^{\circ} \mathrm{C}$ until MIC determination using commercially available broth microdilution plates (CMV1AMAF; Thermo Scientific), which included 10 antimicrobials (Table 1). The MIC was determined following the Clinical and Laboratory Standards Institute standards (CLSI; CLSI, 2013). Quality control strains of Staph. aureus (ATCC 29213; $\mathrm{n}=9$ ) and Streptococcus pneumoniae (ATCC 49619; $\mathrm{n}=3$ ) were included in parallel with the staphylococcal and streptococcal isolates, respectively, during testing. Results for these control strains were within CLSI acceptable range for quality assurance (i.e., $\leq 1$ of 20 tests being out of range; CLSI-VET01A 4E; Table 2). For analysis, MIC at or below the lowest concentration tested were recoded as the lowest MIC, and isolates that were not inhibited by the highest concentration tested were reported as a value twice the highest concentration tested.

\section{Selection of Isolates}

Overall, 984 cows were sampled from 25 herds, and 3,902 milk samples were collected. From these samples, there were 1,285 isolates that were either Staph. aureus, CNS, Strep. dysgalactiae, or Strep. uberis (Table 3). For the 11 herds that had used cloxacillin-ampicillin DCT, a total of 250 isolates of Staph. aureus, CNS, or streptococci were obtained; of these, 247 were selected for MIC determination. For the 8 herds that used cephalonium $\mathrm{DCT}$, and from the 7 organic herds, there were 566 and 469 eligible isolates, respectively. A random selection of these isolates was chosen from each herd type for MIC determination, such that the number of each species was $110 \%$ of the number of isolates from herds that had used cloxacillin-ampicillin DCT (Table 3).

\section{Statistical Analyses}

The primary hypothesis was that the prevalence of resistance among bacterial isolates would not differ among isolates from cows previously treated with

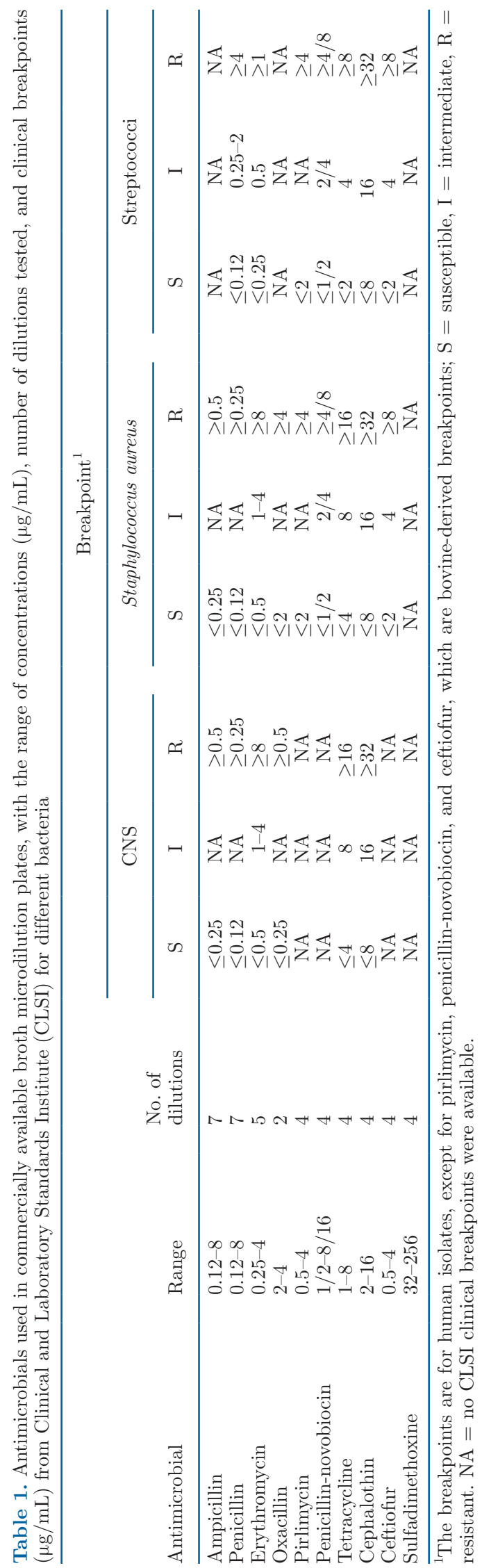




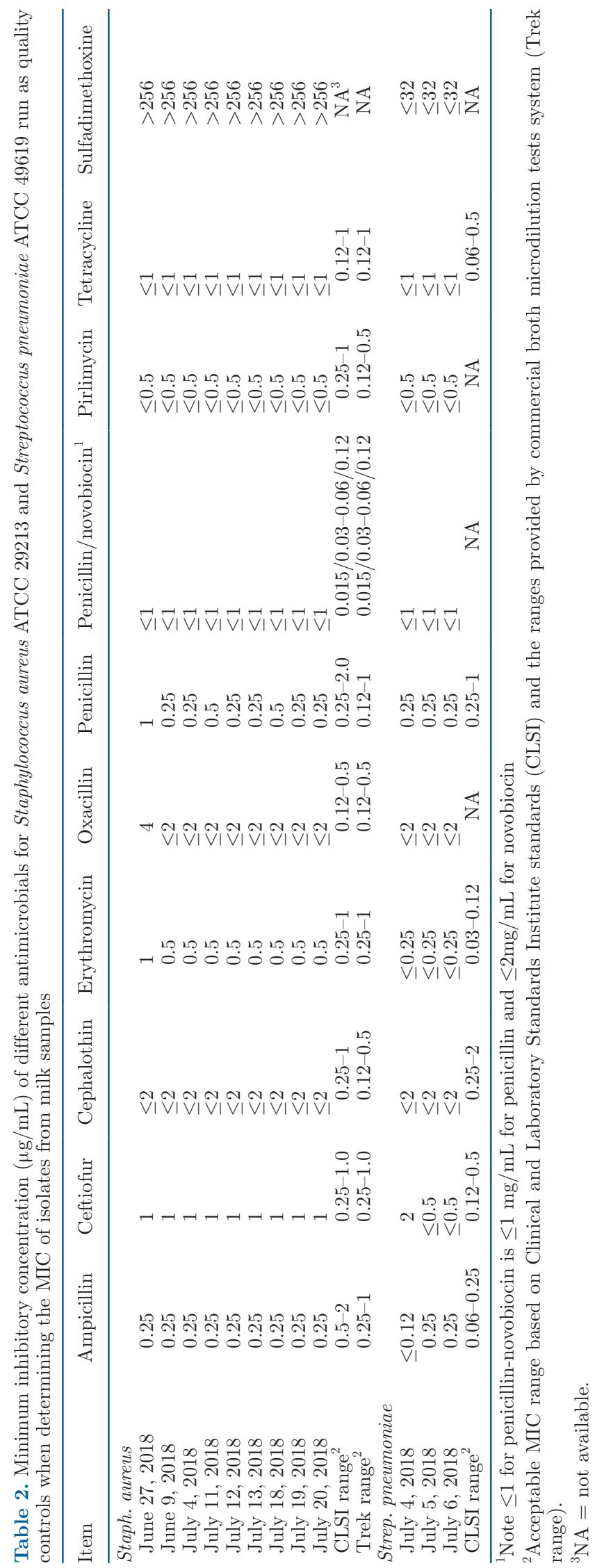

cephalonium or ampicillin-cloxacillin DCT or from the organic herds.

The experimental unit was the isolate. The mean total mass of antimicrobials and mass of each antimicrobial class used per kilogram of liveweight per year in each herd were compared between herds that used cloxacillin-ampicillin or cephalonium DCT-using oneway ANOVA.

The percentage distribution of MIC of each antimicrobial for isolates of CNS, Staph. aureus, Strep. dysgalactiae, and Strep. uberis from herds that used cephalonium or cloxacillin-ampicillin DCT or from organic herds were plotted and visually assessed for a bimodal distribution. In addition, the $\mathrm{MIC}_{50}$ and $\mathrm{MIC}_{90}$ of isolates were calculated for each antimicrobial for different bacteria cultured from herds that used cephalonium or cloxacillin-ampicillin DCT or from organic herds.

The distribution of MIC for isolates of CNS, Staph. aureus, and Strep. uberis were compared between isolates from herds that used cephalonium or cloxacillinampicillin DCT and from organic herds, for each antimicrobial, using binomial or multinomial logistic regression. The MIC values for each antimicrobial within each bacterial class were visually assessed and collapsed into categories such that there were 10 or more values within each MIC category. For some antimicrobial-bacteria combinations, the great majority of MIC values were within 1 category such that no further analysis was undertaken with these antimicrobial-bacterial combinations. The logistic regression models included DCT type as the main effect and used robust standard errors to account for clustering of isolates within herd. Estimated marginal means and 95\% confidence intervals were calculated from the final models and presented graphically.

Additionally, using human-derived CLSI breakpoints, CNS and Staph. aureus isolates were categorized as either susceptible or resistant to penicillin. Associations between resistance and potential explanatory variables were initially examined using chi-squared tests. Variables that were associated $(P<0.2)$ were then included in logistic regression models, with a model structure accounting for clustering of gland within cow within herd (i.e., a 3-level model). The likelihood ratio test was used to assess whether a multilevel model accounting for clustering provided a better fit than a logistic regression model. Herd type (use of cephalonium or cloxacillin-ampicillin DCT or organic) was the main explanatory variable. To assess potential confounding due to exposure to antimicrobials other than DCT, the drug treatment records from the current lactation for cows from herds using antimicrobials were also recovered. Cows were coded as having or not having been exposed to other antimicrobials in the current lactation 
Table 3. Total number of isolates cultured (isolates; $\mathrm{n}$ ) and number and percentage (\%) of isolates selected for MIC testing from herds that used cloxacillin-ampicillin (Clox/Amp) or cephalonium dry cow therapy (DCT) or from organic herds

\begin{tabular}{|c|c|c|c|c|c|c|}
\hline \multirow[b]{2}{*}{ Item } & \multicolumn{2}{|c|}{ Clox/Amp DCT } & \multicolumn{2}{|c|}{ Cephalonium DCT } & \multicolumn{2}{|c|}{ Organic } \\
\hline & Isolate (n) & MIC (\%) & Isolate (n) & $\mathrm{MIC}(\%)$ & Isolate (n) & $\mathrm{MIC}(\%)$ \\
\hline Staphylococcus aureus & 100 & $99(99)$ & 287 & $111(39)$ & 151 & $110(73)$ \\
\hline Streptococcus dysgalactiae & 16 & $16(100)$ & 25 & $17(68)$ & 20 & $17(85)$ \\
\hline CNS & 76 & $74(97)$ & 139 & $82(59)$ & 154 & $84(55)$ \\
\hline Total & 250 & $247(98.8)$ & 566 & $273(48.1)$ & 469 & $274(58.2)$ \\
\hline
\end{tabular}

(i.e., from the most recent calving to $30 \mathrm{~d}$ before sampling). Other potential explanatory variables included age (categorized as $3-4,5,6-7$, or $>8$ yr), breed code $(\geq 12 / 16$ defined as purebred Friesian or Jersey, with the remaining cows coded as crossbreds), DIM at sample collection (categorized as $<81,81-99,100-122$ or $>122$ d), and SCC at the most recent herd test (categorized as $<347,347-676,677-1,328$ or $>1,328 \times 1,000$ cells/ $\mathrm{mL})$.

To assess the power of the current study to detect antimicrobial resistance, posthoc power analyses were undertaken by first calculating the intraclass correlation (rho) for penicillin resistance (for CNS, Staph. aureus), penicillin dichotomized as 0.12 versus $\geq 0.25 \mu \mathrm{g} /$ $\mathrm{mL}$ (for Strep. uberis), or tetracycline resistance defined as $>4 \mu \mathrm{g} / \mathrm{mL}$ (for Strep. dysgalactiae). The number of herds from each DCT group, and the average number of isolates within each herd for each bacterial species were calculated. As the average number of isolates within cow was $<1.3$, clustering of quarter within cow was ignored for these analyses. The prevalence of resistance was calculated for isolates from the organic herd, and then the difference in prevalence that was required to be present for there to be a difference detected (power $=0.8 ; P<0.05)$ with the current sample size and cluster size was calculated. Data analysis was undertaken in STATA/SE v15.0 (STATA Corp.).

\section{RESULTS}

\section{Antimicrobial Usage by Farm}

The mean total antimicrobial usage per year (as expressed on a $\mathrm{mg} / \mathrm{kg}$ of live weight basis) in the $3 \mathrm{yr}$ before the study did not differ between farms that used cephalonium or cloxacillin-ampicillin DCT, nor did the usage of any specific class of antimicrobials, except for those antimicrobials used for DCT (Table 4). By design, more first-generation cephalosporins were used on farms that used cephalonium for DCT, and more cloxacillin was used on the farms that used cloxacillinampicillin for DCT $(P<0.001)$. The small amount of first and second generation cephalosporins used on the cloxacillin farms was due to use of cephapirin for intrauterine treatment of endometritis, and 2 farms used a total of 36 and 72 tubes of cephalonium DCT over the $3 \mathrm{yr}$, respectively. The cloxacillin used in the cephalonium farms was related to use of lactating cow intramammary therapy containing cloxacillin (e.g., Orbenin LA, Zoetis Animal Health and Penclox, Virbac), and 224 and 200 tubes of cloxacillin-based DCT in 2015 and 2016 on 2 cephalonium farms, respectively.

\section{Antimicrobial Therapy in the Current Lactation}

Of the 518 cows from which 1 or more isolates were selected for MIC determination, 40 (7.7\%; 95\% CI: 5.6-10.4) had been treated with antimicrobials between calving and $30 \mathrm{~d}$ before the time of sampling. From these 40 cows, 54 isolates which had been exposed to antimicrobials within the lactation were included in the MIC analyses. Among cows previously treated with cephalonium, 33, 3, and 3 isolates were from cows that had been diagnosed with clinical mastitis, intrauterine disease, and lameness, respectively. Among cows treated with cloxacillin-ampicillin, 14 and 1 isolates were from cows treated with clinical mastitis or for unknown reasons, respectively.

\section{Herds and Sampling}

Overall, milk samples were collected from 984 cows, and the mean $( \pm \mathrm{SD})$ number of cows sampled per herd was $37.8 \pm 33.8$ (range 3-166), which represented 12.6 $\pm 12.1 \%$ (range $1.7-59.3 \%$ ) of cows within herds on average. From the 3,902 sampled quarters, a mean of $60.9 \pm 21.1 \%$ (range 13.9-86.5\%) grew no bacteria, 9.4 $\pm 7.9 \%$ (range 0-26.8\%) grew Staph. aureus, and 9.5 $\pm 6.6 \%$ (range $0-31.1 \%$ ) grew streptococci. The proportion of sampled quarters from which Staph. aureus and streptococci were cultured varied among herds and between herds that used cephalonium or cloxacillinampicillin DCT or were organic (Figure 1). 


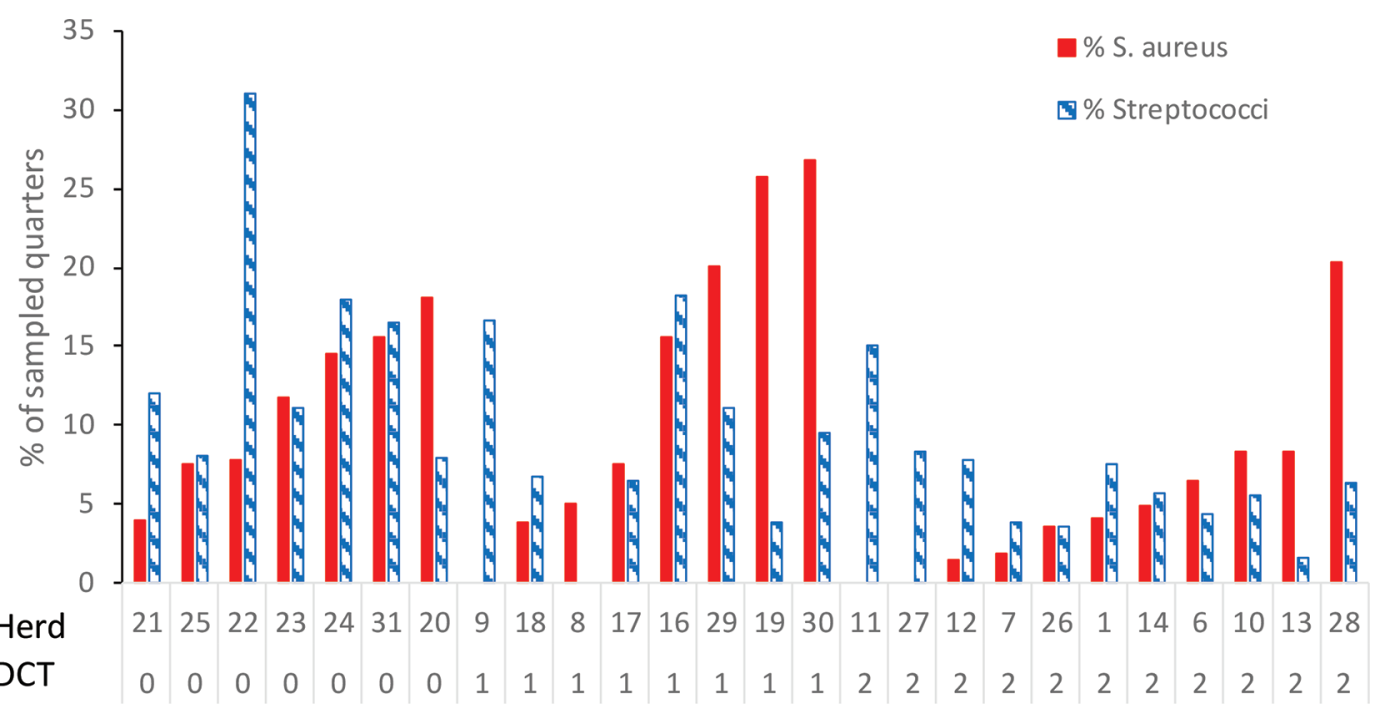

Figure 1. The percentage of quarters from among all quarters sampled from each herd from which Staphylococcus aureus (closed bars) or Streptococcus spp. (cross-hatched bars) were cultured, and with dry cow therapy (DCT) group coded below the x-axis as $0=$ none (i.e., organic), $1=$ cephalonium, and $2=$ cloxacillin-ampicillin.

\section{Minimum Inhibitory Concentrations}

Coagulase-Negative Staphylococci. Of the 240 isolates of CNS, $\leq 6$ had an MIC greater than the highest concentration of antimicrobial tested; however, for sulfadimethoxine, 158 isolates had an MIC above the highest concentration tested (Table 5). Based on CLSI breakpoints, isolates were resistant or had intermediate resistance to ampicillin, cephalothin, erythromycin, oxacillin, penicillin, and tetracycline (Table 5). Bimodal or nonnormal distributions were evident for ampicillin, penicillin, and sulfadimethoxine (Figure 2). The $\mathrm{MIC}_{50}$ and $\mathrm{MIC}_{90}$ for different antimicrobials did not differ by more than one dilution between isolates from herds using different DCT or from organic herds, except for the
$\mathrm{MIC}_{90}$ for ampicillin and penicillin, which were lower in isolates from organic herds than from herds using DCT (Table 6).

At the univariate level, the proportion of penicillinresistant CNS isolates were higher in herds that used cephalonium DCT $(42 / 82 ; 51 \%)$ and from herds that used cloxacillin-ampicillin DCT $(22 / 74 ; 30 \%)$ than from organic herds $(14 / 84 ; 17 \%)(P<0.001)$. Also, at the univariate level, the proportion varied among herds $(P$ $<0.001)$ but was not associated with age category $(P=$ $0.58)$, DIM at sampling $(P=0.66)$, SCC at herd test $(P$ $=0.20)$, breed $(P=0.12)$, or exposure to antimicrobials during the current lactation $(P=0.80)$.

From the final multivariable logistic regression model, the estimated marginal mean $( \pm \mathrm{SE})$ proportion of

Table 4. Annual mean (and SD) mass of antimicrobials used (population corrected units; $\mathrm{mg} / \mathrm{kg}$ of liveweight/ annum) between 2015 and 2017 on farms that had used cephalonium or cloxacillin-ampicillin (Clox/Amp) dry cow therapy (DCT)

\begin{tabular}{|c|c|c|c|c|c|}
\hline \multirow[b]{2}{*}{ Item } & \multicolumn{2}{|c|}{ Cephalonium DCT } & \multicolumn{2}{|c|}{ Clox/Amp DCT } & \multirow[b]{2}{*}{$P$-value } \\
\hline & Mean & $\mathrm{SD}$ & Mean & $\mathrm{SD}$ & \\
\hline Aminoglycoside & 0.137 & 0.086 & 0.112 & 0.021 & 0.66 \\
\hline Cephalosporin first/second ${ }^{1}$ & 1.738 & 0.395 & 0.041 & 0.019 & 0.001 \\
\hline Cephalosporin third/fourth ${ }^{2}$ & 0.057 & 0.048 & 0.081 & 0.038 & 0.34 \\
\hline Macrolide & 0.415 & 0.402 & 0.328 & 0.377 & 0.876 \\
\hline Cloxacillin & 0.241 & 0.27 & 5.068 & 1.173 & 0.001 \\
\hline Extended-spectrum penicillins & 0.017 & 0.016 & 0.058 & 0.047 & 0.071 \\
\hline Narrow spectrum penicillin & 2.201 & 1.185 & 1.428 & 1.111 & 0.201 \\
\hline Sulfonamides & 0.404 & 0.426 & 0.085 & 0.04 & 0.07 \\
\hline Oxytetracyclines & 0.578 & 0.953 & 0.178 & 0.121 & 0.229 \\
\hline
\end{tabular}

${ }^{1}$ First- and second-generation cephalosporins (e.g., cephapirin, cephalonium).

${ }^{2}$ Third- and fourth-generation cephalosporins (e.g., ceftiofur, cefquinome). 
Table 5. Percentage distribution of MIC $(\mu \mathrm{g} / \mathrm{mL})$ of different antimicrobials for 240 CNS isolates cultured from bovine milk samples

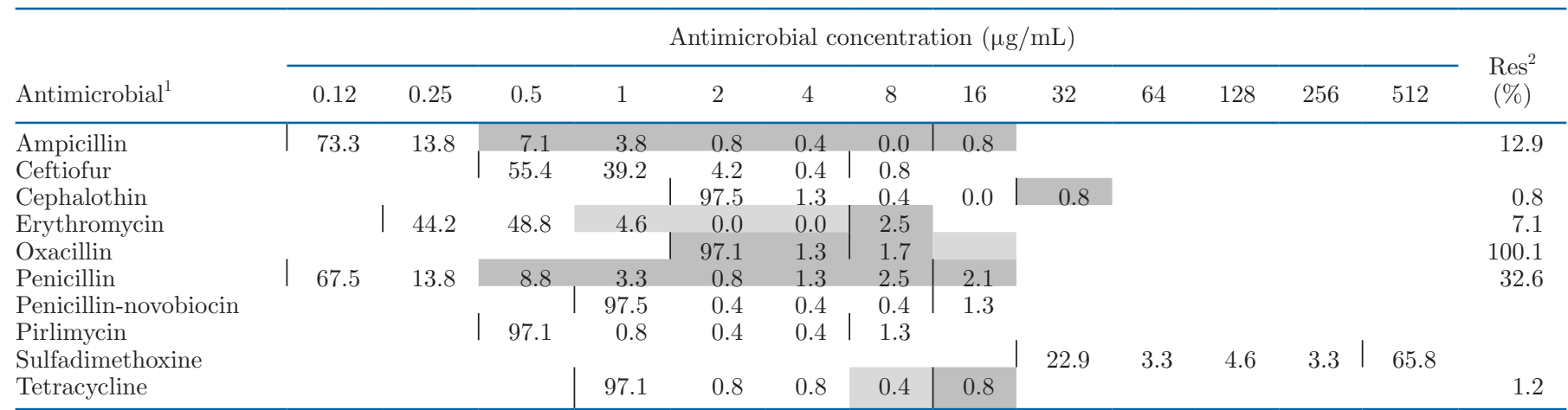

${ }^{1}$ Within an antimicrobial, the vertical lines indicate the range of MIC tested for each antimicrobial. Where an isolate was not inhibited by the maximum concentration tested, the next doubling antimicrobial concentration was assigned as the MIC for that isolate. Results with gray shading indicate isolates defined as resistant by Clinical and Laboratory Standards Institute clinical breakpoints, and those with light gray shading indicate intermediate resistance.

${ }^{2}$ Res $=$ total percentage of isolates defined as being resistant or having intermediate resistance.

penicillin-resistant CNS isolates was greater from herds that used cephalonium DCT $(0.50 \pm 0.07)$ than from herds that used cloxacillin /ampicillin DCT (0.31 \pm $0.06)$ and from organic herds $(0.17 \pm 0.05)$.

The ceftiofur MIC results were categorized as $0.5,1$, or $2 \mu \mathrm{g} / \mathrm{mL}$; the erythromycin MIC were categorized as $0.25,0.5$ or $\geq 1 \mu \mathrm{g} / \mathrm{mL}$; and the sulfadimethoxine MIC were categorized as 32,64 to 256 , and $512 \mu \mathrm{g} / \mathrm{mL}$, respectively, for subsequent multinomial logistic regression. There were more ceftiofur MIC of $0.5 \mathrm{mg} / \mathrm{mL}$ and fewer with an MIC of $2 \mathrm{mg} / \mathrm{mL}$ from the organic isolates than from isolates from herds using DCT (Figure 3). More isolates from herds using cloxacillin-ampicillin DCT had an MIC $\geq 1 \mathrm{mg} / \mathrm{mL}$ for erythromycin than isolates from the other herds (Figure 3). There was no significant difference in the distributions of MIC among isolates from different herd types for sulfadimethoxine (Figure 3). For other antimicrobials, insufficient MIC values outside of the mode value were present to be categorized for further analyses.

Staphylococcus aureus. For the 320 Staph. aureus isolates, $\leq 2$ had an MIC greater than the highest concentration of antimicrobial tested; however, for sulfadimethoxine, 287 isolates had an MIC above the highest concentration tested (Table 7). Based on CLSI breakpoints, isolates were resistant or had intermediate resistance to ampicillin, erythromycin, oxacillin, and penicillin (Table 7). Bimodal distributions were evident for ampicillin and penicillin (Figure 4).

The $\mathrm{MIC}_{50}$ for ampicillin and penicillin were greater by more than 1 dilution for isolates of Staph. aureus from herds that used cephalonium DCT compared with herds that used cloxacillin-ampicillin DCT or from organic herds. The $\mathrm{MIC}_{90}$ for these antimicrobials for isolates from cephalonium DCT herds, and from organic herds, were also greater than for isolates from herds that used cloxacillin-ampicillin DCT (Table 8).

At the univariate level, the proportion of penicillinresistant Staph. aureus isolates was higher in herds that used cephalonium DCT $(76 / 111 ; 68.5 \%)$ than in herds that used cloxacillin-ampicillin DCT $(4 / 99 ; 4.0 \%)$ or organic herds $(32 / 110 ; 29.1 \% ; P<0.001)$. The proportion of penicillin-resistant isolates was not associated with age category $(P=0.40)$, breed $(P=0.34)$, or exposure to antimicrobials within the current lactation $(P=0.45)$, but varied by SCC category $(P=$ $0.005)$ and DIM at sampling $(P=0.001)$. In the final multilevel model, no variables remained significant. The estimated marginal mean $( \pm \mathrm{SE}$ ) proportions of penicillin-resistant isolates did not differ between isolates from herds that used cephalonium $(0.40 \pm 0.14)$ or cloxacillin-ampicillin $(0.14 \pm 0.08)$ DCT or from organic herds $(0.34 \pm 0.11 ; P=0.30)$. The likelihood ratio test indicated a significantly better fit for the multilevel model than for a logistic regression model $(P<0.001)$, indicating significant clustering of isolate within herd.

The ceftiofur MIC results were categorized as 0.5, 1 , or $2 \mu \mathrm{g} / \mathrm{mL}$, the erythromycin MIC was categorized as 0.25 or $\geq 0.5 \mu \mathrm{g} / \mathrm{mL}$, and the sulfadimethoxine MIC were categorized as 32, 64 to 256 , and $512 \mu \mathrm{g} / \mathrm{mL}$, respectively, for subsequent multinomial or binomial logistic regression. There were fewer ceftiofur MIC of $1 \mathrm{\mu g} / \mathrm{mL}$ in the organic isolates compared with isolates from herds using DCT (Figure 5), and there were no other differences among DCT groups in the other MIC categories. More isolates from organic herds had an MIC for sulfadimethoxine of $32 \mu \mathrm{g} / \mathrm{mL}$ compared with isolates from herds using DCT (Figure 5). There was no effect of DCT group on distribution of MIC 
McDougall et al.: ANTIMICROBIAL USE AND BACTERIAL SUSCEPTIBILITY

9150
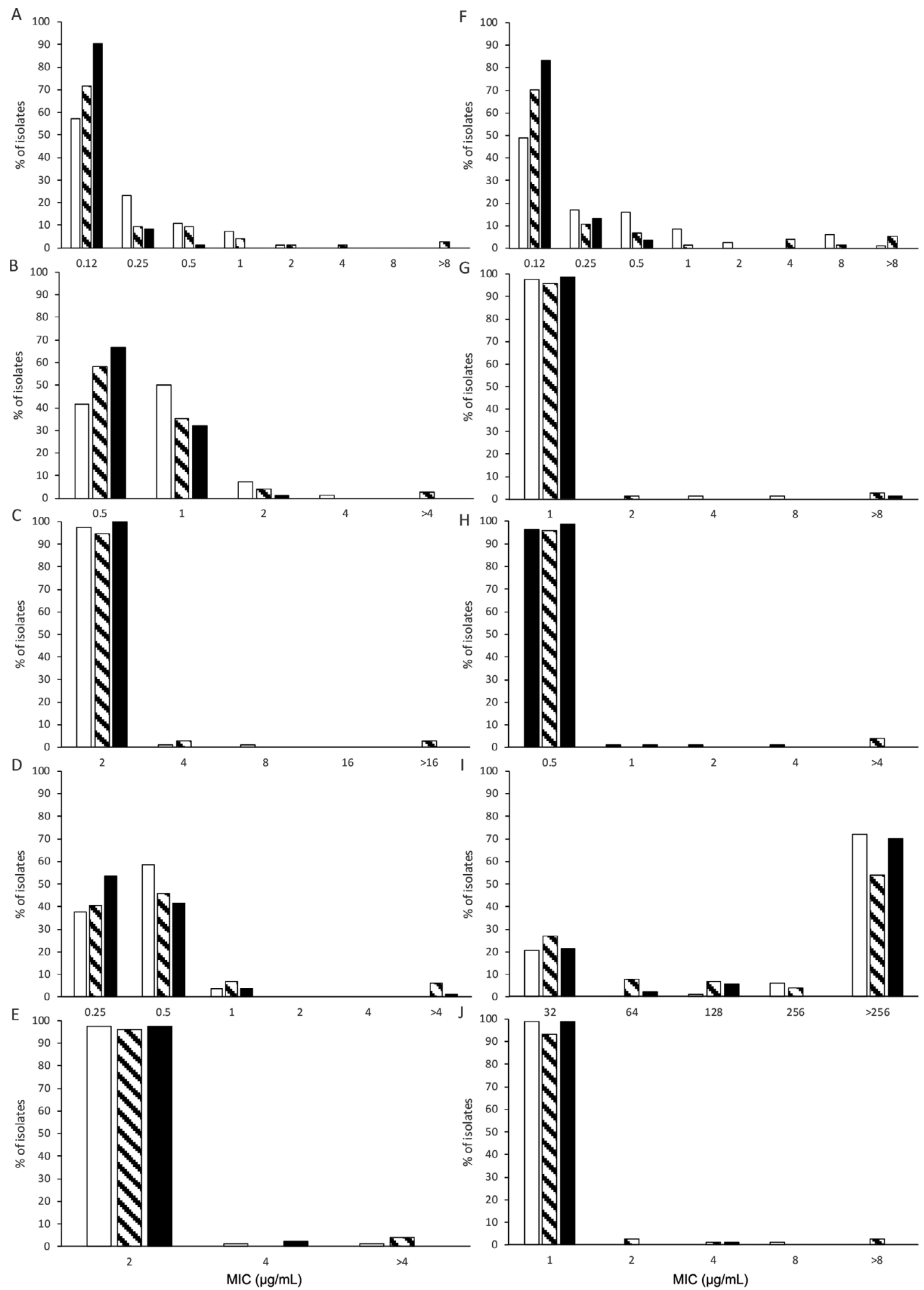

Figure 2. Percentage distribution of the MIC $(\mu \mathrm{g} / \mathrm{mL})$ for $(\mathrm{A})$ ampicillin, (B) ceftiofur, $(\mathrm{C})$ cephalothin, (D) erythromycin, (E) oxacillin, (F) penicillin, $(\mathrm{G})$ penicillin novobiocin, $(\mathrm{H})$ pirlimycin, $(\mathrm{I})$ sulfadimethoxine, and $(\mathrm{J})$ tetracycline of CNS isolates cultured from milk samples from herds that used cephalonium (open bar; $\mathrm{n}=82$ ) dry cow therapy (DCT), herds that used cloxacillin-ampicillin (hatched bar; $\mathrm{n}=74$ ) DCT, or organic herds (black bar; $\mathrm{n}=84$ ).

Journal of Dairy Science Vol. 104 No. 8, 2021 
Table 6. Minimum inhibitory concentrations $(\mu \mathrm{g} / \mathrm{mL})$ of antimicrobials inhibiting growth of $50 \%\left(\mathrm{MIC}_{50}\right)$ and $90 \%\left(\mathrm{MIC}_{90}\right)$ of CNS isolates cultured from herds that used cephalonium $(\mathrm{n}=82)$ or cloxacillin-ampicillin $($ Clox/Amp; $\mathrm{n}=74)$ dry cow therapy $(\mathrm{DCT})$ or from organic herds $(\mathrm{n}=84)$

\begin{tabular}{|c|c|c|c|c|c|c|}
\hline \multirow[b]{2}{*}{ Antimicrobial } & \multicolumn{2}{|c|}{ Cephalonium DCT } & \multicolumn{2}{|c|}{ Clox/Amp DCT } & \multicolumn{2}{|c|}{ Organic } \\
\hline & $\mathrm{MIC}_{50}$ & $\mathrm{MIC}_{90}$ & $\mathrm{MIC}_{50}$ & $\mathrm{MIC}_{90}$ & $\mathrm{MIC}_{50}$ & $\mathrm{MIC}_{90}$ \\
\hline Ampicillin & 0.12 & 0.5 & 0.12 & 0.5 & 0.12 & 0.12 \\
\hline Ceftiofur & 1 & 1 & 0.5 & 1 & 0.5 & 1 \\
\hline Cephalothin & 2 & 2 & 2 & 2 & 2 & 2 \\
\hline Erythromycin & 0.5 & 0.5 & 0.5 & 1 & 0.25 & 0.5 \\
\hline Oxacillin & 2 & 2 & 2 & 2 & 2 & 2 \\
\hline Penicillin & 0.25 & 2 & 0.12 & 1 & 0.12 & 0.25 \\
\hline Penicillin-novobiocin & 1 & 1 & 1 & 1 & 1 & 1 \\
\hline Pirlimycin & 0.5 & 0.5 & 0.5 & 0.5 & 0.5 & 0.5 \\
\hline Sulfadimethoxine & 512 & 512 & 512 & 512 & 512 & 512 \\
\hline Tetracycline & 1 & 1 & 1 & 1 & 1 & 1 \\
\hline
\end{tabular}

for erythromycin $(P=0.93)$. For other antimicrobials, insufficient MIC values outside of the mode value were present to be categorized for further analyses.

Streptococcus dysgalactiae. For the 50 Strep. dysgalactiae isolates, $\leq 4$ had an MIC greater than the highest concentration tested; however, for sulfadimethoxine, 44 isolates had an MIC above the highest concentration tested (Table 9). Based on CLSI breakpoints, isolates were resistant or had intermediate resistance to ceftiofur, erythromycin, penicillin, penicillin-novobiocin, pirlimycin, and tetracycline (Table 9). No bimodal distributions were evident, but there was 1 isolate from a herd that had used cephalonium DCT that had high MIC for many of the antimicrobials (Figure 6). When isolates that were defined as intermediate and resistant for tetracycline using CLSI breakpoints were combined, the proportion of isolates that were not susceptible tended to be lower in herds that used cephalonium DCT $(6 / 17 ; 35 \%)$ than herds that used cloxacillin-ampicillin DCT $(11 / 16 ; 69 \%)$ or organic herds $(12 / 17 ; 71 \%$; $P=$ 0.07). The $\mathrm{MIC}_{50}$ and $\mathrm{MIC}_{90}$ for different antimicrobials did not differ by more than 1 dilution between Strep. dysgalactiae isolates from herds using different DCT or from organic herds, except the $\mathrm{MIC}_{90}$ for erythromycin, which was higher in isolates from herds that used cephalonium DCT than herds that used cloxacillinampicillin DCT or organic herds (Table 10).

Streptococcus uberis. For the 184 Strep. uberis isolates, $\leq 3$ had an MIC greater than the highest concentration of antimicrobial tested; however, for sulfadimethoxine, 180 isolates had an MIC above the highest concentration tested. Based on CLSI breakpoints, isolates were resistant or had intermediate resistance to erythromycin, penicillin, pirlimycin, and tetracycline (Table 11). Bimodal distributions were evident for ampicillin and penicillin (Figure 7). Two isolates were resistant to both to pirlimycin and to erythromycin, and 1 was resistant to pirlimycin and susceptible to erythromycin. The $\mathrm{MIC}_{50}$ and $\mathrm{MIC}_{90}$ for different antimicrobials did not differ by more than 1 dilution between Strep. uberis isolates from herds using different DCT or from organic herds (Table 12). The ceftiofur MIC results were categorized as 0.5 and $\geq 1 \mu \mathrm{g} / \mathrm{mL}$, and the penicillin MIC were categorized as 0.12 or $\geq 0.25 \mu \mathrm{g} / \mathrm{mL}$, respectively, for subsequent binomial logistic regression. There were fewer ceftiofur MIC results $\geq 1 \mu \mathrm{g} / \mathrm{mL}$ and fewer penicillin MIC $\geq 0.25$ $\mu \mathrm{g} / \mathrm{mL}$, respectively, in the organic isolates compared with isolates from herds using DCT (Figure 8).

\section{Posthoc Power Analyses}

The intraclass correlation (rho) was 0.16, 0.76, 0.20, and 0.07 for CNS, Staph. aureus, Strep. uberis, and Strep. dysglactiae, respectively. There was an average of 8 herds per DCT type group, and an average of 9, 15, 8, and 3 isolates per herd tested for CNS, Staph. aureus, Strep. uberis, and Strep. dysglactiae, respectively. For CNS, a $35 \%$ difference (i.e., 0.17 vs. 0.52 prevalence for organic versus DCT-exposed herds) would have been required to have sufficient power to detect a difference. Conversely, the power was 0.83 with the current sample size, with the observed difference in prevalence of resistance of 0.17 versus 0.52 for organic versus cephalonium-exposed isolates, respectively. For Staph. aureus, a difference in $60 \%$ in prevalence of resistance (i.e., 0.3 control vs. 0.9 and DCT treatment group) would have been required to be present to demonstrate a significant difference in the current study. Conversely, the power to see a difference between, for example, the organic and cephalonium-treated herds was 0.41 with the current sample size, and the observed difference in prevalence of penicillin resistance of 0.3 versus 0.69 for organic versus cephalonium-exposed isolates, respectively. For Strep. uberis, we required a difference of $40 \%$ (i.e., a prevalence of 0.3 vs. 0.7 for the organic versus 
A
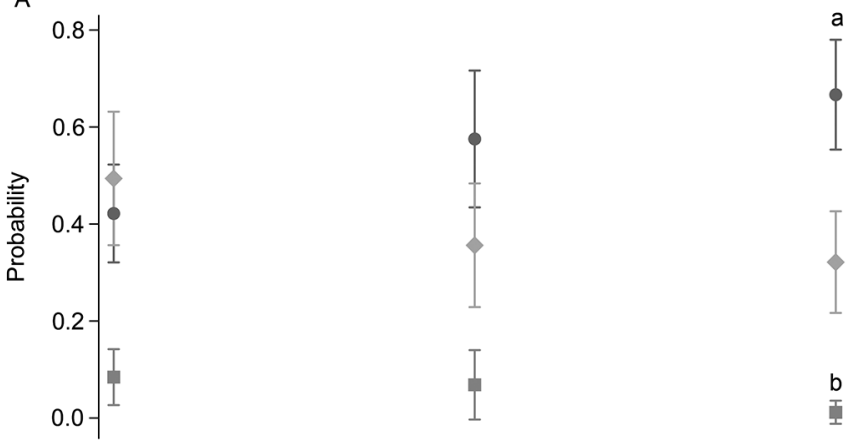

B
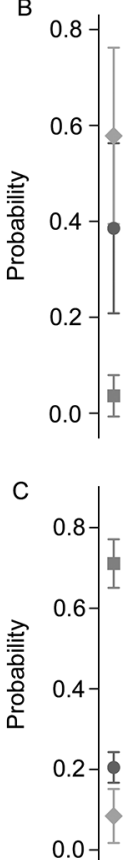

Cephalonium

b

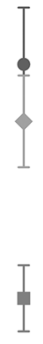

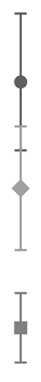

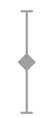

Figure 3. Mean (95\% CI) probability of the MIC $(\mu \mathrm{g} / \mathrm{mL})$ for $(\mathrm{A})$ ceftiofur being 0.5 (circle), 1 (diamond), or 2 (square) $\mathrm{mg} / \mathrm{mL}$, (B) erythromycin being 0.25 (circle), 0.5 (diamond), or $\geq 1$ (square) $\mathrm{mg} /$ $\mathrm{mL}$, and (C) sulfadimethoxine being 32 (circle), 64-256 (diamond), or 512 (square) $\mathrm{mg} / \mathrm{mL}$ for CNS isolates cultured from milk samples from herds that used cephalonium dry cow therapy (DCT), herds that used cloxacillin-ampicillin (Clox/Amp) DCT, or organic herds. The letter a on the ceftiofur graph indicates significantly $(P<0.05)$ more isolates from the organic herds were in the MIC category of $0.5 \mu \mathrm{g} / \mathrm{mL}$, and $\mathrm{b}$ indicates that fewer of the isolates from the organic herd were in the $2 \mu \mathrm{g} / \mathrm{mL}$ category. The letter a on the erythromycin graph indicates significantly more isolates from the cloxacillin-ampicillin DCT herds were in the MIC category of $\geq 1 \mu \mathrm{g} / \mathrm{mL}$.

DCT-exposed isolates, respectively) to find a significant difference. Conversely, we had a power of 0.88 with current sample size with the observed prevalence of elevated MIC of 0.3 versus 0.004 for the control versus cephalonium groups, respectively. For Strep. dysgalactiae, we required a difference of $45 \%$ (i.e., a prevalence of 0.71 versus 0.26 for the organic versus DCT-exposed isolates, respectively) to find a significant difference.
Conversely, with the current sample size, we had a power of 0.53 with the observed prevalence of 0.71 versus 0.35 for the control versus cephalonium group prevalence, respectively.

\section{DISCUSSION}

This study evaluated the MIC of CNS, Staph. aureus, Strep. dysgalactiae, and Strep. uberis isolated from milk of dairy cows with elevated SCC, from organic herds, and herds that predominantly used either cephalonium or cloxacillin/ampicillin-based DCT. Generally, the prevalence of nonsusceptible isolates as defined from CLSI breakpoints was low other than for ampicillin, penicillin, and oxacillin for CNS; ampicillin, and penicillin for Staph. aureus; tetracycline for Strep. dysgalactiae, and penicillin for Strep. uberis. For most antimicrobials, the $\mathrm{MIC}_{50}$ and $\mathrm{MIC}_{90}$ were similar among isolates from organic herds and from herds that used cephalonium and ampicillin-cloxacillin DCT. However, there was evidence of differing MIC distributions for some antimicrobials, suggesting that exposure to antimicrobials was associated with increased MIC for some bacteria. Bimodal distributions of MIC for penicillin were found among Staph. aureus isolates from organic farms. This suggests either that resistant isolates had persisted on those farms from the time when they were using antimicrobials, that resistant Staph. aureus isolates were imported, or that Staph. aureus isolates with high MIC are found in populations not exposed to antimicrobials.

There was sufficient power in the current study to detect differences in resistance or elevated MIC for several of the antimicrobial classes and bacterial species combinations. However, the high intraclass correlation (0.76) for Staph. aureus limited the power to detect a difference in prevalence of penicillin resistance between organic and DCT-using herds. The lower $(\leq 0.2)$ intraclass correlation for the other bacterial species meant that for CNS and S. uberis, sufficient herds and isolates had been tested to demonstrate significant differences. The relatively small number of Strep. dysglactiae isolates recovered in the current study limited the ability to detect difference in MIC distribution between organic and DCT-using herds.

There is a lack of veterinary-defined clinical breakpoints for many bovine mastitis bacterial-antimicrobial combinations. This is partly due to insufficient studies having been done to provide data to define such breakpoints, and due to the way that the CLSI defines a class representative. For example, cephalothin is the class representative of first-generation cephalosporins. The assumption is that the class representative provides an estimate of likely sensitivity that is representative of other antimicrobials in that class. The CLSI also pro- 
Table 7. Percentage distribution of MIC $(\mu \mathrm{g} / \mathrm{mL})$ of different antimicrobials for 320 Staphylococcus aureus isolates cultured from bovine milk samples

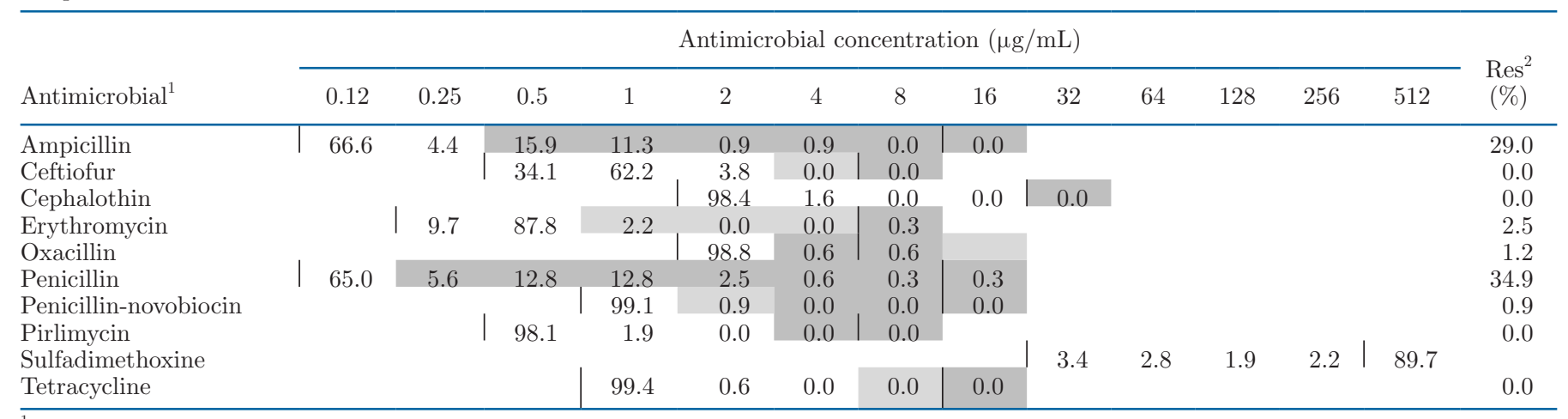

${ }^{1}$ Within an antimicrobial, the vertical lines indicate the range of MIC tested for each antimicrobial. Where an isolate was not inhibited by the maximum concentration tested, the next doubling antimicrobial concentration was assigned as the MIC for that isolate. Results with gray shading indicate isolates defined as resistant by Clinical and Laboratory Standards Institute clinical breakpoints, and those with light gray shading indicate intermediate resistance.

${ }^{2}$ Res $=$ total percentage of isolates defined as being resistant or having intermediate resistance.

vides clinical breakpoints and quality assurance data for the representative antimicrobial. Hence, as it is not the class representative, there are no CLSI breakpoints or quality assurance data for cephalonium. Additionally, cephalonium is not included as an active by any of the commercial providers of broth microdilution plates. Therefore, in this and other studies, class representative antimicrobials are used to determine likely sensitivity, rather than every antimicrobial available in a specific species or market. Ideally, each antimicrobial that is in a product should be tested against isolates exposed to that specific antimicrobial, but the large number of potential antimicrobial-bacterial combinations from all markets around the world preclude such an approach. Hence it is assumed that cephalothin, as the class representative for first-generation cephalosporins, provides an estimate of sensitivity equivalent to those for cephalonium. However, the MIC for cefalexin, cephalonium, cephapirin, and cefazolin for one Staph. aureus isolate (Newbould 305; ATCC 29740) was determined to be $4,0.06,0.125$, and $0.25 \mu \mathrm{g} / \mathrm{mL}$, respectively (Demon et al., 2012). This indicates that the potency of cephalonium is 2 to 67 times that of these other firstgeneration cephalosporins. In the same study, a mouse model demonstrated that higher bacteriological cure rates were achieved by cephalonium and cefazolin than for cefalexin and cephapirin when the same dose $(\mu \mathrm{g} /$ gland) was applied (Demon et al., 2012).

Herds were selected to meet the antimicrobial exposure criteria; then, within herd, only cows with a high SCC were selected for sampling. Only a small subset of the more than 700 herds serviced by the 1 veterinary business met the inclusion criteria. Hence, no other inclusion criteria other than DCT-usage pattern was applied at the herd level. There was variation in the prevalence of intramammary infection and in dominant pathogens among the enrolled herds. This likely reflected previous and current herd management, culling policy, and introduction of animals potentially carrying antimicrobial-resistant bacteria or antimicrobial resistance genes. By design, the antimicrobial sales data on the herds was used to differentiate between those herds that had used cephalonium or cloxacillin-ampicillin as the antimicrobial DCT for the $3 \mathrm{yr}$ preceding the study. It is unknown whether use of a specific class of antimicrobial for DCT is correlated with other mastitis control management. Given the small number of herds in the current study, it is unlikely that further investigation of this will provide any meaningful associations.

Approximately one-third of the Staph. aureus isolates were defined as ampicillin- or penicillin-resistant in the current study using CLSI breakpoints. This agrees with estimates of 27 and $28 \%$ of isolates being defined as ampicillin- and penicillin-resistant, respectively, from a previous New Zealand study (McDougall et al., 2014). Internationally, penicillin resistance among bovine Staph. aureus isolates has been present since at least the 1950s and is common in all dairy industries (Vintov et al., 2003). There was substantial between-herd variation in the prevalence of Staph. aureus and in the proportion of resistant isolates. Differences in efficacy of mastitis control measures (for example, use of teat sprays), culling policies, or biosecurity measures potentially account for the observed differences in prevalence.

In the current study, the prevalence of streptococcal isolates that were resistant to penicillin was low, although $25 \%$ of Strep. uberis isolates showed intermediate resistance to penicillin. Similarly, 1 and $30 \%$ of Strep. uberis isolates from New Zealand cows were reported as being resistant or having intermediate re- 

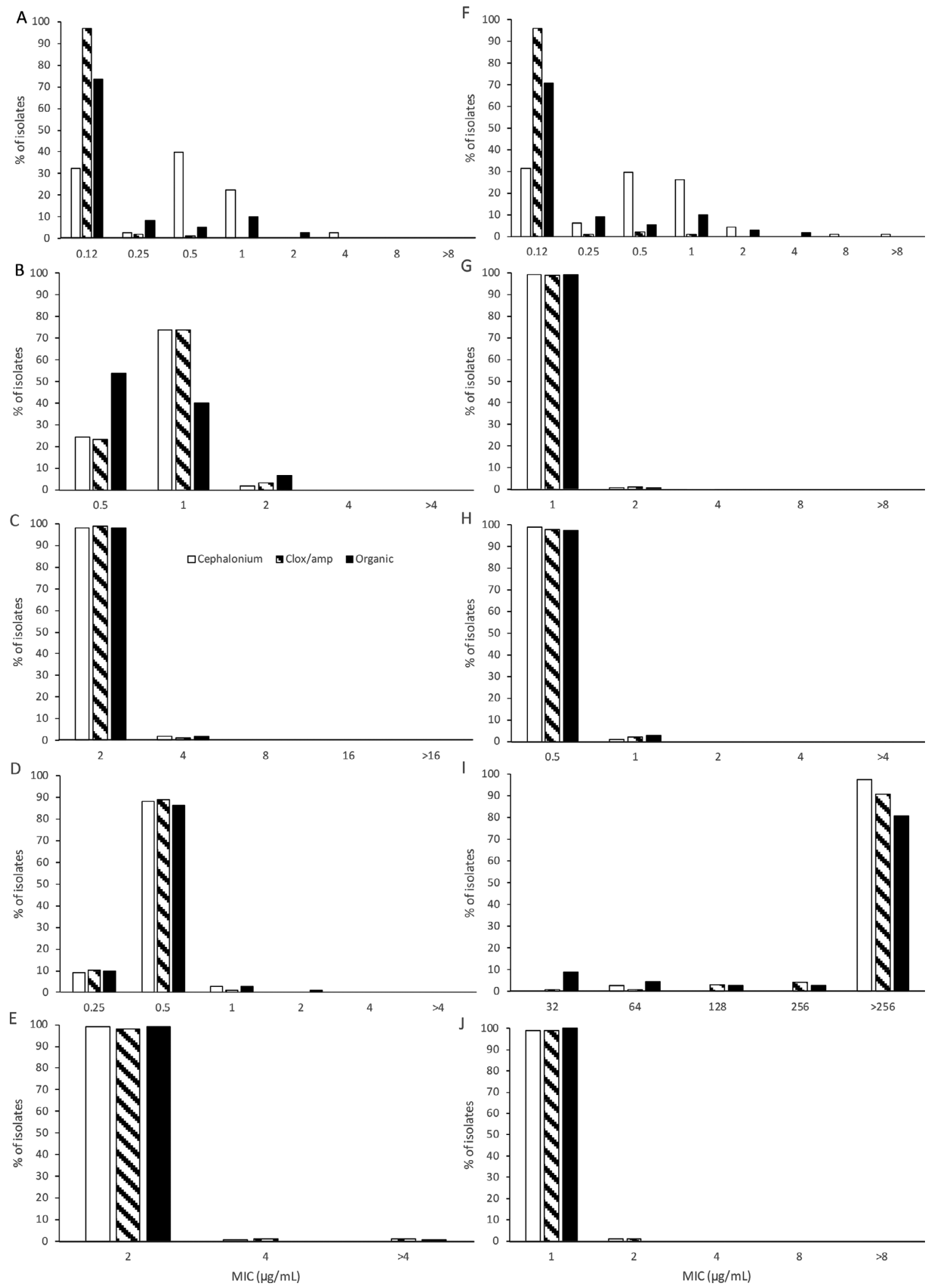

Figure 4. Percentage distribution of the MIC $(\mu \mathrm{g} / \mathrm{mL})$ for $(\mathrm{A})$ ampicillin, (B) ceftiofur, (C) cephalothin, (D) erythromycin, (E) oxacillin, (F) penicillin, $(\mathrm{G}$ ) penicillin novobiocin, $(\mathrm{H})$ pirlimycin, $(\mathrm{I})$ sulfadimethoxine, and $(\mathrm{J})$ tetracycline of Staphylococcus aureus isolates cultured from milk samples from herds that used cephalonium (open bar; $\mathrm{n}=111$ ) dry cow therapy (DCT), herds that used cloxacillin-ampicillin (hatched bar; $\mathrm{n}=99) \mathrm{DCT}$, or organic herds (black bar; $\mathrm{n}=110$ ). 
sistance to penicillin, respectively (McDougall et al., 2014). Of the 50 Strep. dysgalactiae isolates in the current study, $58 \%$ had an MIC for tetracycline, indicating intermediate resistance or resistance $(\geq 8 \mu \mathrm{g} / \mathrm{mL})$, and the prevalence of isolates that were not susceptible was lower in herds that used cephalonium DCT compared with herds that used cloxacillin-ampicillin DCT or in organic herds. Studies from France and California have also reported a high proportion of Strep. dysgalactiae isolates having MIC $\geq 8 \mu \mathrm{g} / \mathrm{mL}$ tetracycline (GuérinFaublée et al., 2002; Rossitto et al., 2002). In contrast, a Swedish study reported that only $12 \%$ of Strep. dysgalactiae isolates had MIC $\geq 8 \mu \mathrm{g} / \mathrm{mL}$ tetracycline (Bengtsson et al., 2009). Clearly, there is wide variation in prevalence of tetracycline resistance among bovine streptococci internationally. Resistance to tetracycline may be conferred by tet $O$, tetS , and tet $M$ genes. These may be associated with plasmids, and are found in widely varying strain types, indicating horizontal gene transfer is likely occurring (Haenni et al., 2010). The collection of more isolates and genomic analyses would be useful to determine mechanisms of resistance among Strep. dysglactiae isolates from herds using different DCT.

Minimum inhibitory concentration data are discrete, interval-censored, ordinal, and are commonly skewed or bimodal. Minimum inhibitory concentration data have been commonly categorized as susceptible or resistant, and modeled using logistic regression. However, this approach may not be appropriate or feasible where no clinical breakpoints exist, or where there is no clear bimodal distribution among MIC that would allow definition of an epidemiological cut-point. Additionally, this approach results in a loss of information, such that changes over time in MIC distributions within categories may not be detected. Such changes have been shown to occur, for example, in methicillinresistant staphylococcal infections in humans, and were associated with poorer clinical outcomes, even within the CLSI susceptible range (Yeh et al., 2012). Recently, a Canadian data set of MIC for Escherichia coli was analyzed using linear regression (following $\log _{10}$ transformation of MIC), generalized linear mixed models, Tobit, logistic regression, Cox's proportional hazards (using complimentary log-log models), and multinomial and ordinal regression approaches (MacKinnon et al., 2018). They reported that logistic and multinomial models consistently meet modeling assumptions. Hence, we used a similar approach in the current study. Due to the presence of no, or small numbers of, isolates within some MIC categories, MIC categories were collapsed such that there were at least 10 isolates in each MIC category for analysis. For some antimicrobial-bacterial combinations, the great majority of isolates had a very similar MIC, and such categorization was not feasible.

For the CNS isolates in the current study, the $\mathrm{MIC}_{90}$ for ampicillin and penicillin were lower in isolates from organic herds than from herds using cephalonium or cloxacillin-ampicillin DCT. In addition, CNS isolates from organic herds were more likely to have an MIC in the lowest category tested $(0.5 \mu \mathrm{g} / \mathrm{mL})$ and less likely to have an isolate in the higher MIC categories $(\geq 2 \mu \mathrm{g} /$ $\mathrm{mL}$ ) for ceftiofur.

Among the Staph. aureus isolates, there was evidence of resistance to ampicillin and penicillin. The presence of $\beta$-lactamases results in elevated MIC in isolates for ampicillin and penicillin, and the blaZ gene has been demonstrated among Staph. aureus isolates with elevated MIC in New Zealand (Steele and McDougall, 2014). In the present study, there was no evidence among the Staph. aureus isolates of elevated MIC, indicating no resistance, to the first-generation cephalosporins, cephalothin, or oxacillin. The first-generation cephalosporins are effective against Staph. aureus, even in the presence of $\beta$-lactamases (Harrison and Bratcher, 2008). Despite methicillin-resistant Staph. aureus being reported in

Table 8. Minimum inhibitory concentrations $(\mu \mathrm{g} / \mathrm{mL})$ of antimicrobials inhibiting growth of $50 \%\left(\mathrm{MIC}_{50}\right)$ and $90 \%\left(\mathrm{MIC}_{90}\right)$ of Staphylococcus aureus isolates cultured from herds that used cephalonium $(\mathrm{n}=111)$ or cloxacillin-ampicillin (Clox/Amp; $\mathrm{n}=99)$ dry cow therapy $(\mathrm{DCT})$ or from organic herds $(\mathrm{n}=110)$

\begin{tabular}{|c|c|c|c|c|c|c|}
\hline \multirow[b]{2}{*}{ Antimicrobial } & \multicolumn{2}{|c|}{ Cephalonium DCT } & \multicolumn{2}{|c|}{ Clox/Amp DCT } & \multicolumn{2}{|c|}{ Organic } \\
\hline & $\mathrm{MIC}_{50}$ & $\mathrm{MIC}_{90}$ & $\mathrm{MIC}_{50}$ & $\mathrm{MIC}_{90}$ & $\mathrm{MIC}_{50}$ & $\mathrm{MIC}_{90}$ \\
\hline Ampicillin & 0.5 & 1 & 0.12 & 0.12 & 0.12 & 1 \\
\hline Ceftiofur & 1 & 1 & 1 & 1 & 0.5 & 1 \\
\hline Cephalothin & 2 & 2 & 2 & 2 & 2 & 2 \\
\hline Erythromycin & 0.5 & 0.5 & 0.5 & 0.5 & 0.5 & 0.5 \\
\hline Oxacillin & 2 & 2 & 2 & 2 & 2 & 2 \\
\hline Penicillin & 0.5 & 1 & 0.12 & 0.12 & 0.12 & 1 \\
\hline Penicillin-novobiocin & 1 & 1 & 1 & 1 & 1 & 1 \\
\hline Pirlimycin & 0.5 & 0.5 & 0.5 & 0.5 & 0.5 & 0.5 \\
\hline Sulfadimethoxine & 512 & 512 & 512 & 512 & 512 & 512 \\
\hline Tetracycline & 1 & 1 & 1 & 1 & 1 & 1 \\
\hline
\end{tabular}



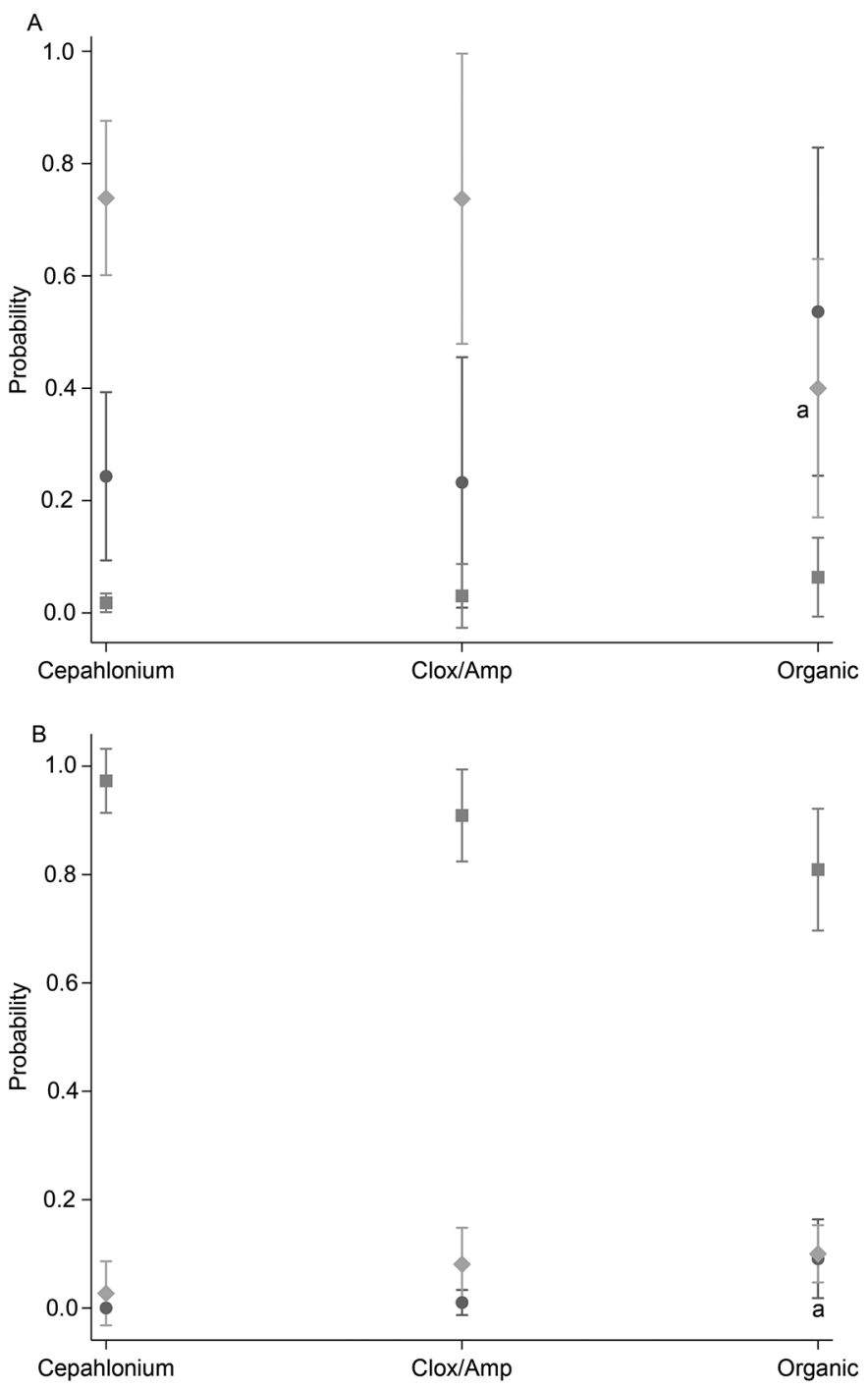

Figure 5. Mean $(95 \%$ CI) probability of the MIC $(\mu \mathrm{g} / \mathrm{mL})$ for $(A)$ ceftiofur being 0.5 (circle), 1 (diamond), or 2 (square) $\mathrm{mg} / \mathrm{mL}$, and (B) sulfadimethoxine being 32 (circle), 64 to 256 (diamond), or 512 (square) $\mathrm{mg} / \mathrm{mL}$ for Staphylococcus aureus isolates cultured from milk samples from herds that used cephalonium dry cow therapy (DCT), herds that used cloxacillin-ampicillin (Clox/Amp) DCT, or organic herds. The letter a on the ceftiofur graph indicates significantly $(P<$ $0.05)$ more isolates from the organic herds were in the MIC category of $1 \mu \mathrm{g} / \mathrm{mL}$. The letter a on the sulfadimethoxine graph indicates significantly more isolates from the organic herds were in the MIC category of $32 \mu \mathrm{g} / \mathrm{mL}$.

dairy industries around the world, there is currently no evidence that it is present in New Zealand dairy herds (Grinberg et al., 2008). In the current study, genotypic testing for methicillin-resistant Staphylococcus aureus (MRSA) was not undertaken, but the observed phenotypes suggest that isolates were unlikely to be MRSA.

The $\mathrm{MIC}_{90}$ for ampicillin and penicillin was lower in Staph. aureus isolates from herds using ampicillincloxacillin DCT than from herds that had used cepha- lonium DCT or that were organic. Similarly, at the bivariate level, the MIC distributions for these antimicrobials differed between isolates from herds using ampicillin-cloxacillin or cephalonium DCT, but not between isolates from herds that used cephalonium DCT compared with isolates from organic herds. Previous studies have found that the risk of being above $\mathrm{MIC}_{90}$ only differed between Staph. aureus isolates from bulk tank milk from organic or conventional dairy farms for ciprofloxacin (in Wisconsin herds) and albamycin (in Danish herds) among 15 antimicrobials tested (Sato et al., 2004), and there was no difference between Scandinavian conventional or organic herds in the percentage of herds in which penicillin-resistant Staph. aureus was found, or the proportion of cows with Staph. aureus isolates that were penicillin-resistant (Bennedsgaard et al., 2006; Garmo et al., 2010). Similarly, a Swiss study comparing 60 organic and 60 conventional dairy farms found no difference in the proportion of gram-positive mastitis isolates that were resistant, as defined by CLSI breakpoints (Roesch et al., 2006). As Staph. aureus is difficult to cure, and as ongoing cow to cow transmission is likely to occur even in well-managed herds (Zadoks et al., 2011), it is possible that resistant Staph. aureus may persist in an organic herd for many years following cessation of antimicrobial use. There may also be a risk of introduction of resistant Staph. aureus when cattle are purchased. Although the current study was designed to assess antimicrobial susceptibly among isolates from herds that had used either cephalonium or ampicillin-cloxacillin DCT or had been organic for $>3$ yr, variation among herds in MIC may in part be due to introduction of resistant isolates, rather than selection for, or perpetuation of, such isolates within a herd. Additionally, other mastitis management practices may affect the probability that resistant isolates remain in the herd. For example, selection criteria for culling of cows may remove cows infected with resistant isolates.

The MIC for most antimicrobials were generally low among streptococcal isolates, and they were generally susceptible to penicillin. This suggests that narrow spectrum penicillin compounds should remain the frontline antimicrobial treatment for streptococci. Although there were differences in the MIC distributions among Strep. uberis isolates from herds that had used DCT and from organic herds, in almost all cases, this was due to a higher proportion of isolates from organic herds being present in the lowest concentration tested. Where the MIC are below the clinical breakpoint, it is currently unclear as to whether these variations in MIC distribution are clinically significant.

In the current study, $\beta$-lactams accounted for approximately 80 and $92 \%$ of the total antimicrobial use in herds that used cephalonium and cloxacillin-ampicillin 
Table 9. Percentage distribution of MIC $(\mu \mathrm{g} / \mathrm{mL})$ of different antimicrobials for 50 Streptococcus dysgalactiae isolates cultured from bovine milk samples

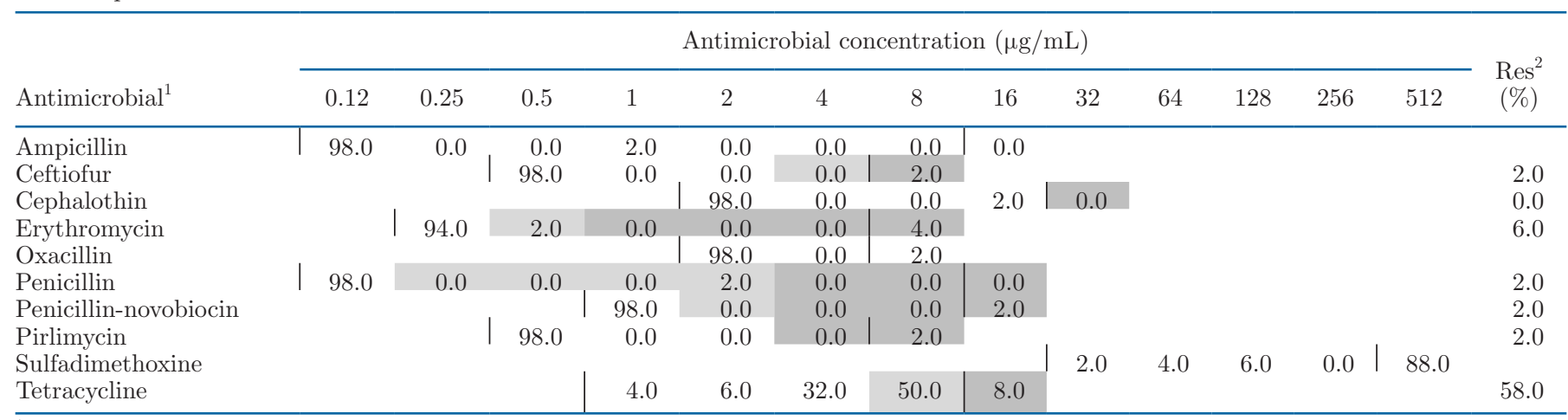

${ }^{1}$ Within an antimicrobial, the vertical lines indicate the range of MIC tested for each antimicrobial. Where an isolate was not inhibited by the maximum concentration tested, the next doubling antimicrobial concentration was assigned as the MIC for that isolate. Results with gray shading indicate isolates defined as resistant by Clinical and Laboratory Standards Institute clinical breakpoints, and those with light gray shading indicate intermediate resistance.

${ }^{2}$ Res $=$ total percentage of isolates defined as being resistant or having intermediate resistance.

DCT, respectively. Hence, it is not surprising that MIC were elevated among the majority of the $\beta$-lactam antimicrobials tested. Conversely, no differences between organic and DCT-using farms in MIC distributions were detected for erythromycin, penicillin-novobiocin, or for oxacillin, the class representative for cloxacillin. The majority of isolates across all bacterial species had an MIC for oxacillin of $2 \mu \mathrm{g} / \mathrm{mL}$, with a very small number having MIC of 4 or $>4 \mu \mathrm{g} / \mathrm{mL}$. It has recently been reported that mutations of the penicillin-binding protein $2 \mathrm{x}$ are associated with increases in the MIC for oxacillin among Strep. uberis and are found in isolates from around the world (McDougall et al., 2020). In the current study, similar proportions of Strep. uberis isolates had an elevated MIC for oxacillin among organic herds and those using DCT. This suggests that exposure to antimicrobials does not necessarily explain the presence of elevated MIC for oxacillin among Strep. uberis isolates.

For the lincosamide pirlimycin, there was no difference between organic and DCT-using farms in MIC distributions. Pirlimycin was in the New Zealand marketplace for some years but has not been sold within the timeframe of the current study. Potentially, resistance to pirlimycin may have arisen due to use of the macrolide tylosin, which is commonly used parenterally in New Zealand for treatment of mastitis. As lincosamides and macrolides have a common target on the $23 \mathrm{~S}$ ribosomal RNA on the 50S ribosomal subunit, methylation of this prevents binding, inducing resistance for both classes of antimicrobial (Schmitt-Van de Leemput and Zadoks, 2007). Two Strep. uberis isolates were resistant both to erythromycin and pirlimycin, suggesting that cross-resistance was indeed occurring, albeit at a low incidence (i.e., approximately $1.6 \%$ of Strep. uberis isolates).
Associations among exposure to antimicrobials and resistance are complex. Both positive and negative associations between exposure to specific antimicrobials and presence of resistance genes in E. coli recovered from feces have been reported (Birkegård et al., 2017). In that study, exposure to tetracyclines resulted in an increase in the presence of 1 tetracycline resistance gene, tet $W$, but a reduction in the incidence of a second tetracycline resistance gene, tet $O$, and in the macrolide resistance gene ermB. Unexplained associations, including a positive association between the use of extended-spectrum penicillins and the presence of the tetracycline-resistant gene, tet $M$, and a negative association with the sulfonamide resistance gene, sulI, were also found. Additionally, modeling of the presence of resistance genes based on antimicrobial exposure, farm size, animal age, and animal movements was only able to explain between 11 and $42 \%$ of the variance seen. The authors concluded that factors other than direct antimicrobial exposure must be explaining the presence of antimicrobial resistance genes in this population. Other studies have demonstrated that phenotypic and genotypic resistance against tetracyclines and macrolides may be found without exposure to those classes of antimicrobials (Dunlop et al., 1998; Holman and Chénier, 2013; Agga et al., 2014).

However, associations between antimicrobial use and antimicrobial resistance have been demonstrated in cattle. Increasing use of third and fourth generation cephalosporins was associated with an increased probability that extended-spectrum $\beta$-lactamase or AmpCproducing $E$. coli isolates were recovered on farm, as was use of antimicrobials for every case of clinical mastitis, compared with selective use of antimicrobial for clinical mastitis (Gonggrijp et al., 2016). Similarly, in dairy 

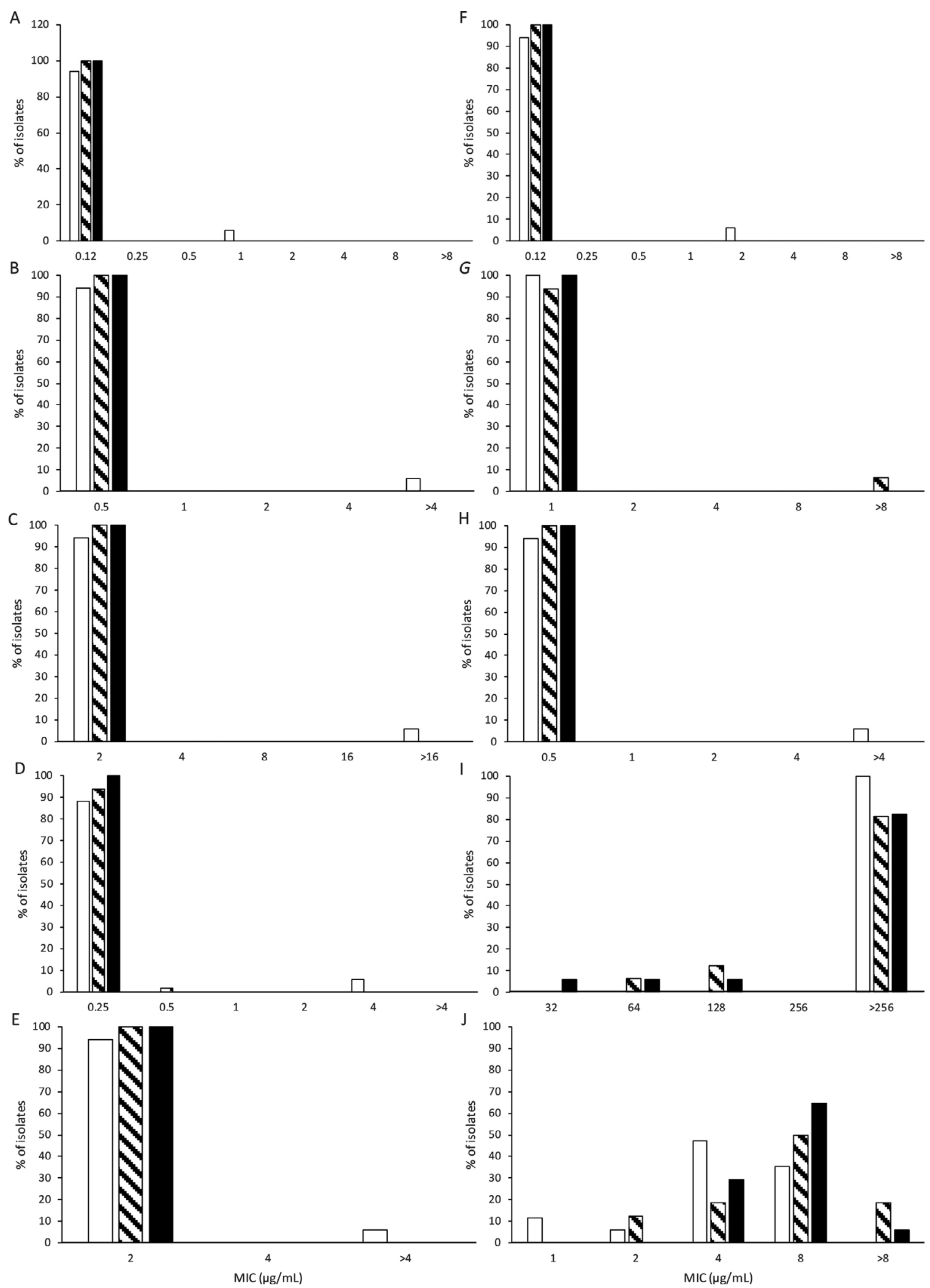

Figure 6. Percentage distribution of the MIC $(\mu \mathrm{g} / \mathrm{mL})$ for $(\mathrm{A})$ ampicillin, (B) ceftiofur, (C) cephalothin, (D) erythromycin, (E) oxacillin, (F) penicillin, (G) penicillin novobiocin, (H) pirlimycin, (I) sulfadimethoxine, and (J) tetracycline of Streptococcus dysgalactiae isolates cultured from milk samples from herds that used cephalonium (open bar; $\mathrm{n}=17$ ) dry cow therapy (DCT), herds that used cloxacillin-ampicillin (hatched bar; $\mathrm{n}=16$ ) DCT, or organic herds (black bar; $\mathrm{n}=17$ ). 
Table 10. Minimum inhibitory concentrations $(\mu \mathrm{g} / \mathrm{mL})$ of antimicrobials inhibiting growth of $50 \%\left(\mathrm{MIC}_{50}\right)$ and $90 \%\left(\mathrm{MIC}_{90}\right)$ of Streptococcus dysgalactiae isolates cultured from herds that used cephalonium $(\mathrm{n}=17)$ or cloxacillin-ampicillin (Clox/Amp; $\mathrm{n}=16)$ dry cow therapy (DCT) or from organic herds $(\mathrm{n}=17)$

\begin{tabular}{|c|c|c|c|c|c|c|}
\hline \multirow[b]{2}{*}{ Antimicrobial } & \multicolumn{2}{|c|}{ Cephalonium DCT } & \multicolumn{2}{|c|}{ Clox/Amp DCT } & \multicolumn{2}{|c|}{ Organic } \\
\hline & $\mathrm{MIC}_{50}$ & $\mathrm{MIC}_{90}$ & $\mathrm{MIC}_{50}$ & $\mathrm{MIC}_{90}$ & $\mathrm{MIC}_{50}$ & $\mathrm{MIC}_{90}$ \\
\hline Ampicillin & 0.12 & 0.12 & 0.12 & 0.12 & 0.12 & 0.12 \\
\hline Ceftiofur & 0.5 & 0.5 & 0.5 & 0.5 & 0.5 & 0.5 \\
\hline Cephalothin & 2 & 2 & 2 & 2 & 2 & 2 \\
\hline Erythromycin & 0.25 & 8 & 0.25 & 0.25 & 0.25 & 0.25 \\
\hline Oxacillin & 2 & 2 & 2 & 2 & 2 & 2 \\
\hline Penicillin & 0.12 & 0.12 & 0.12 & 0.12 & 0.12 & 0.12 \\
\hline Penicillin-novobiocin & 1 & 1 & 1 & 1 & 1 & 1 \\
\hline Pirlimycin & 0.5 & 0.5 & 0.5 & 0.5 & 0.5 & 0.5 \\
\hline Sulfadimethoxine & 512 & 512 & 512 & 512 & 512 & 512 \\
\hline Tetracycline & 4 & 8 & 8 & 16 & 8 & 8 \\
\hline
\end{tabular}

Table 11. Percentage distribution of MIC $(\mu \mathrm{g} / \mathrm{mL})$ of different antimicrobials for 184 Streptococcus uberis isolates cultured from bovine milk samples

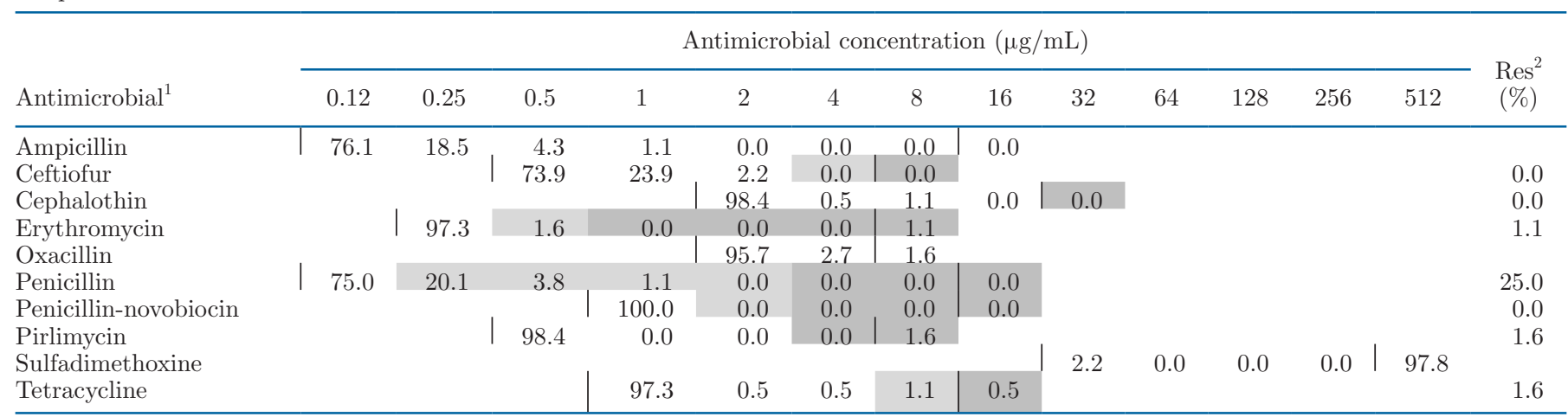

${ }^{1}$ Within an antimicrobial, the vertical lines indicate the range of MIC tested for each antimicrobial. Where an isolate was not inhibited by the maximum concentration tested, the next doubling antimicrobial concentration was assigned as the MIC for that isolate. Results with gray shading indicate isolates defined as resistant by Clinical and Laboratory Standards Institute clinical breakpoints, and those with light gray shading indicate intermediate resistance.

${ }^{2}$ Res $=$ total percentage of isolates defined as being resistant or having intermediate resistance.

Table 12. Minimum inhibitory concentrations $(\mu \mathrm{g} / \mathrm{mL})$ of antimicrobials inhibiting growth of $50 \%\left(\mathrm{MIC}_{50}\right)$ and $90 \%\left(\mathrm{MIC}_{90}\right)$ of Streptococcus uberis isolates cultured from herds that used cephalonium $(\mathrm{n}=63)$ or cloxacillin-ampicillin (Clox/Amp; $\mathrm{n}=58)$ dry cow therapy (DCT) or from organic herds $(\mathrm{n}=63)$

\begin{tabular}{|c|c|c|c|c|c|c|}
\hline \multirow[b]{2}{*}{ Antimicrobial } & \multicolumn{2}{|c|}{ Cephalonium DCT } & \multicolumn{2}{|c|}{ Clox/Amp DCT } & \multicolumn{2}{|c|}{ Organic } \\
\hline & $\mathrm{MIC}_{50}$ & $\mathrm{MIC}_{90}$ & $\mathrm{MIC}_{50}$ & $\mathrm{MIC}_{90}$ & $\mathrm{MIC}_{50}$ & $\mathrm{MIC}_{90}$ \\
\hline Ampicillin & 0.12 & 0.25 & 0.12 & 0.25 & 0.12 & 0.12 \\
\hline Ceftiofur & 0.5 & 1 & 0.5 & 1 & 0.5 & 0.5 \\
\hline Cephalothin & 2 & 2 & 2 & 2 & 2 & 2 \\
\hline Erythromycin & 0.25 & 0.25 & 0.25 & 0.25 & 0.25 & 0.25 \\
\hline Oxacillin & 2 & 2 & 2 & 2 & 2 & 2 \\
\hline Penicillin & 0.12 & 0.25 & 0.12 & 0.25 & 0.12 & 0.12 \\
\hline Penicillin-novobiocin & 1 & 1 & 1 & 1 & 1 & 1 \\
\hline Pirlimycin & 0.5 & 0.5 & 0.5 & 0.5 & 0.5 & 0.5 \\
\hline Sulfadimethoxine & 512 & 512 & 512 & 512 & 512 & 512 \\
\hline Tetracycline & 1 & 1 & 1 & 1 & 1 & 1 \\
\hline
\end{tabular}


<smiles>I[I-]I(I)I(I)I</smiles> 
farms in Canada, associations were found between the amounts of specific antimicrobials used for treatment and the probability of resistant or multidrug-resistant Staph. aureus and CNS (Saini et al., 2012; Nobrega et al., 2018).

Factors other than current antimicrobial usage have been associated with the presence of antimicrobial resistance on dairy farms, potentially explaining persistence of antimicrobial resistance in the face of declining, or no further use of, antimicrobials. Thus, prevalence of antimicrobial resistance on a specific farm may not be correlated with antimicrobial usage on that farm. For example, animal movements may increase the risk of introducing resistant isolates or genes, and use of heavy metals or disinfectants may result in cross selection for antimicrobial resistance among bovine isolates (Davies and Wales, 2019). Sublethal exposure to some disinfectants such as chlorhexidine, widely used in the dairy industry as teat disinfectant, may increase the frequency of conjugated transfer of antimicrobial resistance genes (Jutkina et al., 2018).

There is also evidence for within-farm transfer of antimicrobial resistance. For example, AmpC-producing $E$. coli were more common in adult animals on farms where ceftiofur was used, even if the specific animals in question were not treated (Tragesser et al., 2006). Transfer between farms has been demonstrated for livestock-associated methicillin-resistant Staph. aureus (Locatelli et al., 2017). These data suggest that although appropriate use of antimicrobials is important for managing the risk of antimicrobial resistance, other management strategies such as good hygiene; disease control processes including vaccination, wildlife control, and pest access to farms; minimal animal movements onto farm; not sharing transport trucks; and improvement of general animal health are also important (Duse et al., 2015; Davies and Wales, 2019). In the context of the current study, the presence of antimicrobial resistance on farms that had been organic for at least $3 \mathrm{yr}$, and in some cases up to $19 \mathrm{yr}$, demonstrated that ceasing use of antimicrobials does not necessarily result in elimination of antimicrobial resistance. Thus, policy or regulatory decisions to reduce or eliminate antimicrobial use on dairy farms may not have the intended effect of reducing prevalence of antimicrobial resistance. This is not to infer that inappropriate antimicrobial usage should not be reduced, but rather to point out that the prevalence of antimicrobial resistance may not decline immediately.

We conclude that, aside from ampicillin and penicillin resistance among CNS and Staph. aureus isolates and tetracycline resistance among Strep. dysgalactiae isolates, antimicrobial resistance to commonly used antimicrobials among mastitis pathogens in New Zealand is rare. However, the MIC for some antimicrobials was higher for isolates from herds using DCT compared with organic herds. This suggests that some selection pressure is occurring in herds using antimicrobials relative to organic herds. It should be noted that the differences in MIC distributions were relatively small. Even though data supporting clinical breakpoints is currently lacking for many bacteria-antimicrobial combinations, the MIC were such that antimicrobials likely remain clinically effective. It should also be noted that antimicrobial resistance was present among some isolates from organic herds, suggesting factors other than

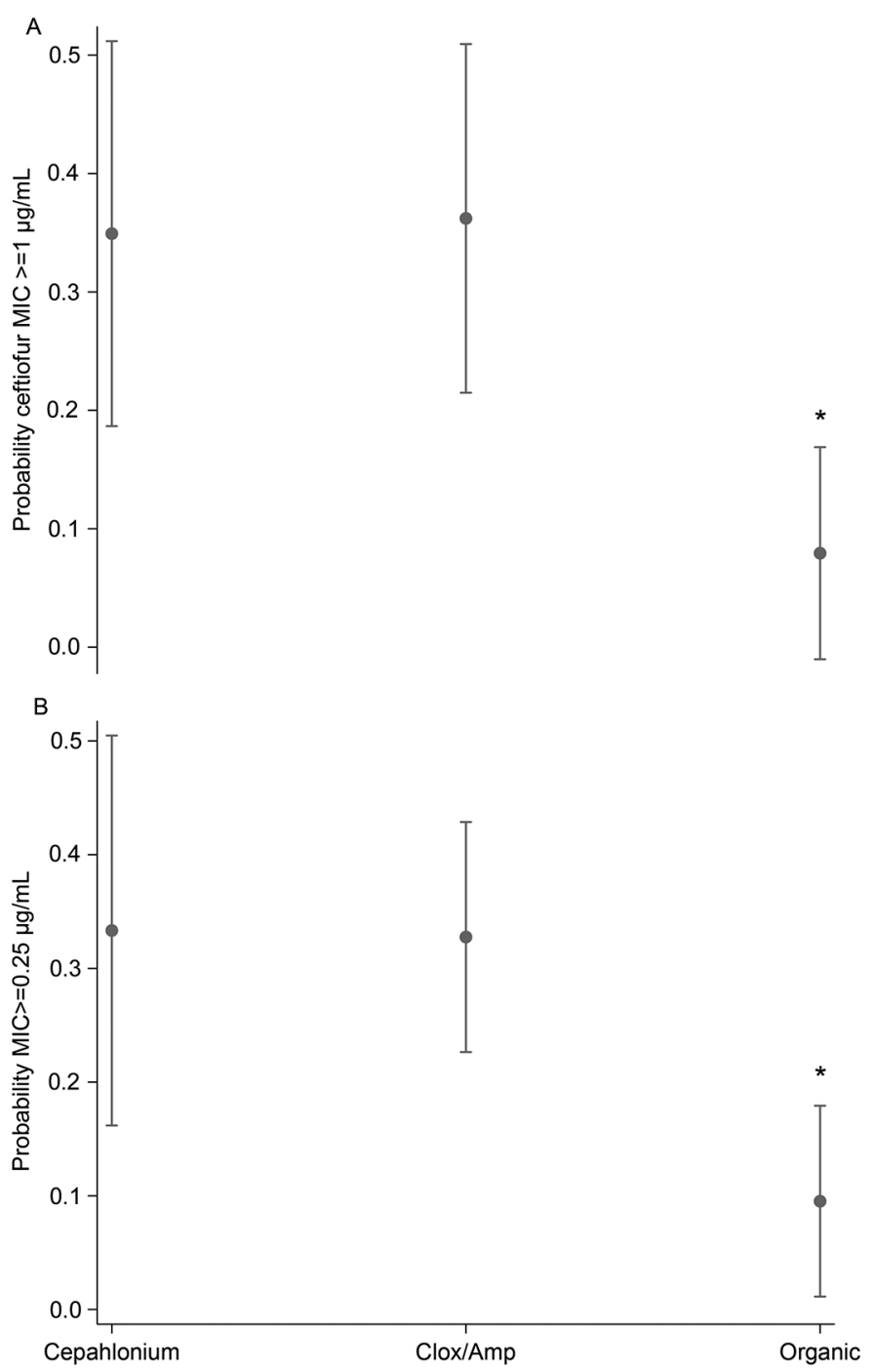

Figure 8. Mean (95\% CI) probability of the MIC $(\mu \mathrm{g} / \mathrm{mL})$ for $(\mathrm{A})$ ceftiofur being $\geq 1 \mathrm{mg} / \mathrm{mL}$, and (B) penicillin MIC being $\geq 0.25 \mathrm{mg} /$ $\mathrm{mL}$ for Streptococcus uberis isolates cultured from milk samples from herds that used cephalonium dry cow therapy (DCT), cloxacillin-ampicillin (Clox/Amp) DCT or from organic herds. The asterisks indicate significantly $(P<0.05)$ fewer isolates from the organic herds were in the MIC category of $\geq 1 \mu \mathrm{g} / \mathrm{mL}$ or $0.25 \mu \mathrm{g} / \mathrm{mL}$ for ceftiofur or penicillin, respectively. 
current antimicrobial use may be contributing to presence of resistant isolates within herds. The duration of persistence of antimicrobial resistance, once present in herd, and the risk of importation of resistant isolates, remains unknown and requires further study.

\section{ACKNOWLEDGMENTS}

The cooperation of herd owners and staff to allow collection of milk samples and access to data is greatly appreciated. The technical team of Cognosco are thanked for accessing and entering data, milk collection, and laboratory work. The laboratory team, including Libby Graham, Ali Karkaba, Yvette McPherson, and Nigel Peirce are thanked for their work. The on-farm sampling was undertaken by Elizabeth Blythe, Anna Maisey, Bev Brownlie, Jacqui Tyler, Janielen da Silva, Sharon Copping and Saleh Mohamed. Funding for this study was provided by MSD Animal Health (Upper Hutt, New Zealand). David Dymock is employed by MSD, Upper Hutt, New Zealand. MSD retails a number of antimicrobial dry cow therapy products.

\section{REFERENCES}

ACVM. 2019. Antibiotic Sales Analysis 2017. Accessed Aug. 28, 2020. URL. https://www.biosecurity.govt.nz/dmsdocument/37886/ direct

Agga, G. E., H. M. Scott, R. G. Amachawadi, T. G. Nagaraja, J. Vinasco, J. Bai, B. Norby, D. G. Renter, S. S. Dritz, J. L. Nelssen, and M. D. Tokach. 2014. Effects of chlortetracycline and copper supplementation on antimicrobial resistance of fecal Escherichia coli from weaned pigs. Prev. Vet. Med. 114:231-246. https://doi .org/10.1016/j.prevetmed.2014.02.010.

Bengtsson, B., H. E. Unnerstad, T. Ekman, K. Artursson, M. NilssonÖst, and K. P. Waller. 2009. Antimicrobial susceptibility of udder pathogens from cases of acute clinical mastitis in dairy cows. Vet. Microbiol. 136:142-149. https://doi.org/10.1016/j.vetmic.2008.10 .024 .

Bennedsgaard, T. W., S. M. Thamsborg, F. M. Aarestrup, C. Enevoldsen, M. Vaarst, and A. B. Christoffersen. 2006. Resistance to penicillin of Staphylococcus aureus isolates from cows with high somatic cell counts in organic and conventional dairy herds in Denmark. Acta Vet. Scand. 48:24. https://doi.org/10.1186/1751-0147-48-24.

Birkegård, A. C., T. Halasa, K. Græsbøll, J. Clasen, A. Folkesson, and N. Toft. 2017. Association between selected antimicrobial resistance genes and antimicrobial exposure in Danish pig farms. Sci. Rep. 7:9683. https://doi.org/10.1038/s41598-017-10092-9.

CLSI. 2013. Performance standards for antimicrobial disk and dilution susceptibility tests for bacteria isolated from animals; Approved standard. VET01-A4. Fourth edition ed. Clinical and Laboratory Standards Institute.

Compton, C., and S. McDougall. 2014. Patterns of antibiotic sales to Waikato dairy farms. VetScript 27:22-24.

Davies, R., and A. Wales. 2019. Antimicrobial resistance on farms: A review including biosecurity and the potential role of disinfectants in resistance selection. Compr. Rev. Food Sci. Food Saf. 18:753774. https://doi.org/10.1111/1541-4337.12438.

de Jong, A., F. El Garch, S. Simjee, H. Moyaert, M. Rose, M. Youala, and E. Siegwart. 2018. Monitoring of antimicrobial susceptibility of udder pathogens recovered from cases of clinical mastitis in dairy cows across Europe: VetPath results. Vet. Microbiol. 213:7381. https://doi.org/10.1016/j.vetmic.2017.11.021.
Demon, D., C. Ludwig, K. Breyne, D. Guédé, J.-C. Dörner, R. Froyman, and E. Meyer. 2012. The intramammary efficacy of first generation cephalosporins against Staphylococcus aureus mastitis in mice. Vet. Microbiol. 160:141-150. https://doi.org/10.1016/j vetmic.2012.05.017.

Dodd, F. H., D. R. Westgarth, F. K. Neave, and R. G. Kingwill. 1969. Mastitis - the strategy of control. J. Dairy Sci. 52:689-695. https: //doi.org/10.3168/jds.S0022-0302(69)86631-2.

Dohoo, I. R., and K. E. Leslie. 1991. Evaluation of changes in somatic cell counts as indicators of new intramammary infections. Prev. Vet. Med. 10:225-237. https://doi.org/10.1016/0167 $-5877(91) 90006-\mathrm{N}$.

Dohoo, I. R., J. Smith, S. Andersen, D. F. Kelton, and S. Godden. 2011. Diagnosing intramammary infections: Evaluation of definitions based on a single milk sample. J. Dairy Sci. 94:250-261. https://doi.org/10.3168/jds.2010-3559.

Dunlop, R. H., S. A. McEwen, A. H. Meek, R. C. Clarke, W. D. Black, and R. M. Friendship. 1998. Associations among antimicrobial drug treatments and antimicrobial resistance of fecal Escherichia coli of swine on 34 farrow-to-finish farms in Ontario, Canada. Prev. Vet. Med. 34:283-305. https://doi.org/10.1016/S0167 -5877(97)00095-0.

Duse, A., K. P. Waller, U. Emanuelson, H. E. Unnerstad, Y. Persson, and B. Bengtsson. 2015. Risk factors for quinolone-resistant Escherichia coli in feces from preweaned dairy calves and postpartum dairy cows. J. Dairy Sci. 98:6387-6398. https://doi.org/10.3168/ jds.2015-9453.

Garmo, R. T., S. Waage, S. Sviland, B. I. F. Henriksen, O. Osteras, and O. Reksen. 2010. Reproductive performance, udder health, and antibiotic resistance in mastitis bacteria isolated from Norwegian Red cows in conventional and organic farming. Acta Vet. Scand. 52:11. https://doi.org/10.1186/1751-0147-52-11.

Gonggrijp, M. A., I. M. G. A. Santman-Berends, A. E. Heuvelink, G. J. Buter, G. van Schaik, J. J. Hage, and T. J. G. M. Lam. 2016. Prevalence and risk factors for extended-spectrum $\beta$-lactamaseand AmpC-producing Escherichia coli in dairy farms. J. Dairy Sci. 99:9001-9013. https://doi.org/10.3168/jds.2016-11134.

Grinberg, A., D. D. Kingsbury, I. R. Gibson, B. M. Kirby, H. J. Mack, and D. Morrison. 2008. Clinically overt infections with methicillinresistant Staphylococcus aureus in animals in New Zealand: A pilot study. N. Z. Vet. J. 56:237-242. https://doi.org/10.1080/00480169 .2008.36840.

Guérin-Faublée, V., G. Carret, and P. Houffschmitt. 2003. In vitro activity of 10 antimicrobial agents against bacteria isolated from cows with clinical mastitis. Vet. Rec. 152:466-471. https://doi .org/10.1136/vr.152.15.466.

Guérin-Faublée,., V., F. Tardy, C. Bouveron, and G. Carret. 2002. Antimicrobial susceptibility of Streptococcus species isolated from clinical mastitis in dairy cows. Int. J. Antimicrob. Agents 19:219226. https://doi.org/10.1016/S0924-8579(01)00485-X.

Haenni, M., E. Saras, S. Bertin, P. Leblond, J.-Y. Madec, and S. Payot. 2010. Diversity and mobility of integrative and conjugative elements in bovine isolates of Streptococcus agalactiae, S. dysgalactiae ssp. dysgalactiae, and S. uberis. Appl. Environ. Microbiol. 76:7957-7965. https://doi.org/10.1128/AEM.00805-10.

Halasa, T., M. Nielen, A. C. Whist, and O. Østerås. 2009a. Metaanalysis of dry cow management for dairy cattle. Part 2. Cure of existing intramammary infections. J. Dairy Sci. 92:3150-3157. https://doi.org/10.3168/jds.2008-1741.

Halasa, T., O. Osteras, H. Hogeveen, T. van Werven, and M. Nielen. 2009b. Meta-analysis of dry cow management for dairy cattle. Part 1. Protection against new intramammary infections. J. Dairy Sci. 92:3134-3149. https://doi.org/10.3168/jds.2008-1740.

Harrison, C. J., and D. Bratcher. 2008. Cephalosporins: A Review. Pediatr. Rev. 29:264-267. https://doi.org/10.1542/pir.29-8-264.

Holman, D. B., and M. R. Chénier. 2013. Impact of subtherapeutic administration of tylosin and chlortetracycline on antimicrobial resistance in farrow-to-finish swine. FEMS Microbiol. Ecol. 85:1-13. https://doi.org/10.1111/1574-6941.12093.

Jutkina, J., N. P. Marathe, C. F. Flach, and D. G. J. Larsson. 2018. Antibiotics and common antibacterial biocides stimulate horizon- 
tal transfer of resistance at low concentrations. Sci. Total Environ. 616-617:172-178. https://doi.org/10.1016/j.scitotenv.2017.10.312.

Locatelli, C., P. Cremonesi, A. Caprioli, V. Carfora, A. Ianzano, A. Barberio, S. Morandi, A. Casula, B. Castiglioni, V. Bronzo, and P. Moroni. 2017. Occurrence of methicillin-resistant Staphylococcus aureus in dairy cattle herds, related swine farms, and humans in contact with herds. J. Dairy Sci. 100:608-619. https://doi.org/10 $.3168 /$ jds.2016-11797.

MacKinnon, M. C., D. L. Pearl, C. A. Carson, E. J. Parmley, and S. A. McEwen. 2018. A comparison of modelling options to assess annual variation in susceptibility of generic Escherichia coli isolates to ceftiofur, ampicillin and nalidixic acid from retail chicken meat in Canada. Prev. Vet. Med. 160:123-135. https://doi.org/10.1016/ j.prevetmed.2018.08.009.

Markovec, J. A., and P. Ruegg. 2003. Antimicrobial resistance of bacteria isolated from dairy cow milk samples submitted for bacterial culture: 8,905 samples (1994-2001). J. Am. Vet. Med. Assoc. $222: 1582-1589$.

McDougall, S., L. Clausen, H.-J. Ha, I. Gibson, M. Bryan, N. Hadjirin, E. Lay, C. Raisen, X. Ba, O. Restif, J. Parkhill, and M. A. Holmes. 2020. Mechanisms of beta-lactam resistance of Streptococcus uberis isolated from bovine mastitis cases. Vet. Microbiol. 242:108592. https://doi.org/10.1016/j.vetmic.2020.108592.

McDougall, S., H. Hussein, and K. Petrovski. 2014. Antimicrobial resistance in Staphylococcus aureus, Streptococcus uberis and Streptococcus dysgalactiae from dairy cows with mastitis. N. Z. Vet. J. 62:68-76. https://doi.org/10.1080/00480169.2013.843135.

Middleton, J. R., L. K. Fox, G. Pighetti, and C. Petersson-Wolfe. 2017. Laboratory Handbook on Bovine Mastitis 3rd ed. NMC.

Nobrega, D. B., J. De Buck, and H. W. Barkema. 2018. Antimicrobial resistance in non-aureus staphylococci isolated from milk is associated with systemic but not intramammary administration of antimicrobials in dairy cattle. J. Dairy Sci. 101:7425-7436. https:/ /doi.org/10.3168/jds.2018-14540.

Pol, M., and P. L. Ruegg. 2007. Treatment practices and quantifications of antimicrobial drug usage in conventional and organic dairy farms in Wisconsin. J. Dairy Sci. 90:249-261. https://doi.org/10 .3168/jds.S0022-0302(07)72626-7.

Poutrel, B., S. Bareille, G. Lequeux, and F. Leboeuf. 2018. Prevalence of mastitis pathogens in France: Antimicrobial susceptibility of Staphylococcus aureus, Streptococcus uberis and Escherichia coli. J. Vet. Sci. Technol. 9:522. https://doi.org/10.4172/2157-7579 .1000522 .

Rajala-Schultz, P. J., K. L. Smith, J. S. Hogan, and B. C. Love. 2004. Antimicrobial susceptibility of mastitis pathogens from first lactation and older cows. Vet. Microbiol. 102:33-42. https://doi.org/10 .1016/j.vetmic.2004.04.010.

Roesch, M., V. Perreten, M. G. Doherr, W. Schaeren, M. Schällibaum, and J. W. Blum. 2006. Comparison of antibiotic resistance of udder pathogens in dairy cows kept on organic and on conventional farms. J. Dairy Sci. 89:989-997. https://doi.org/10.3168/jds.S0022 -0302(06)72164-6.

Rossitto, P. V., L. Ruiz, Y. Kikuchi, K. Glenn, K. Luiz, J. L. Watts, and J. S. Cullor. 2002. Antibiotic susceptibility patterns for environmental streptococci isolated from bovine mastitis in central California dairies. J. Dairy Sci. 85:132-138. https://doi.org/10 .3168/jds.S0022-0302(02)74061-7.
Saini, V., J. T. McClure, D. T. Scholl, T. J. DeVries, and H. W. Barkema. 2012. Herd-level association between antimicrobial use and antimicrobial resistance in bovine mastitis Staphylococcus aureus isolates on Canadian dairy farms. J. Dairy Sci. 95:1921-1929. https://doi.org/10.3168/jds.2011-5065.

Sato, K., T. W. Bennedsgaard, P. C. Bartlett, R. J. Erskine, and J. B. Kaneene. 2004. Comparison of antimicrobial susceptibility of Staphylococcus aureus isolated from bulk tank milk in organic and conventional dairy herds in the midwestern United States and Denmark. J. Food Prot. 67:1104-1110. https://doi.org/10.4315/ 0362-028X-67.6.1104.

Schmitt-Van de Leemput, E., and R. N. Zadoks. 2007. Genotypic and phenotypic detection of macrolide and lincosamide resistance in Streptococcus uberis. J. Dairy Sci. 90:5089-5096. https://doi.org/ $10.3168 / \mathrm{jds} .2007-0101$.

Steele, N., and S. McDougall. 2014. Effect of prolonged duration therapy of subclinical mastitis in lactating dairy cows using penethamate hydriodide. N. Z. Vet. J. 62:38-46. https://doi.org/10.1080/ 00480169.2013.830350.

Stevens, M., S. Piepers, K. Supre, J. Dewulf, and S. De Vliegher. 2016. Quantification of the antimicrobial consumption in adult cattle on dairy herds in Flanders, Belgium, and the association with udder health, milk quality and production performances. J. Dairy Sci. 99:2118-2130. https://doi.org/10.3168/jds.2015-10199.

Tenhagen, B-A., G. Köster, J. Wallmann, and W. Heuwieser. 2006. Prevalence of mastitis pathogens and their resistance against antimicrobial agents in dairy cows in Brandenburg, Germany. J. Dairy Sci. 89:2542-2551. https://doi.org/10.3168/jds.S0022 -0302(06)72330-X.

Tragesser, L. A., T. E. Wittum, J. A. Funk, P. L. Winokur, and P. J. Rajala-Schultz. 2006. Association between ceftiofur use and isolation of Escherichia coli with reduced susceptibility to ceftriaxone from fecal samples of dairy cows. Am. J. Vet. Res. 67:1696-1700. https://doi.org/10.2460/ajvr.67.10.1696.

Vintov, J., F. M. Aarestrup, C. Elsberg Zinn, and J. E. Olsen. 2003. Phage types and antimicrobial resistance among Danish bovine Staphylococcus aureus isolates since the 1950s. Vet. Microbiol. 97:63-72. https://doi.org/10.1016/S0378-1135(03)00186-X.

Walsh, C. 2000. Molecular mechanisms that confer antibacterial drug resistance. Nature 406:775-781. https://doi.org/10.1038/35021219.

Yeh, Y.-C., K.-M. Yeh, T.-Y. Lin, S.-K. Chiu, Y.-S. Yang, Y.-C. Wang, and J.-C. Lin. 2012. Impact of vancomycin MIC creep on patients with methicillin-resistant Staphylococcus aureus bacteremia. J. Microbiol. Immunol. Infect. 45:214-220. https://doi.org/10 .1016/j.jmii.2011.11.006.

Zadoks, R. N., J. R. Middleton, S. McDougall, J. Katholm, and Y. H. Schukken. 2011. Molecular epidemiology of mastitis pathogens of dairy cattle and comparative relevance to humans. J. Mammary Gland Biol. Neoplasia 16:357-372. https://doi.org/10.1007/s10911 -011-9236-y.

\section{ORCIDS}

S. McDougall @ https://orcid.org/0000-0002-9865-0532 